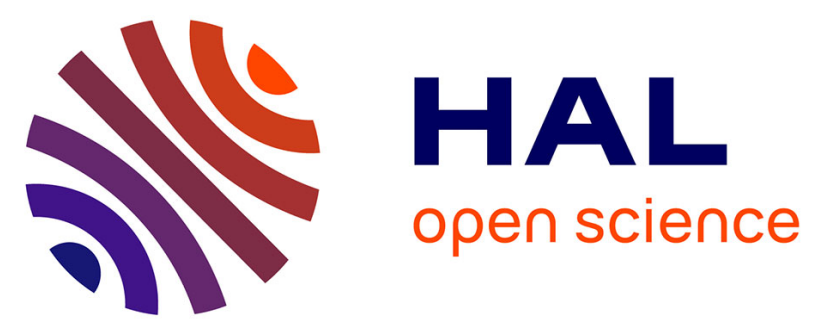

\title{
Interfacial study of surface-modified ZrO2 nanoparticles with thioctic acid for the selective recovery of palladium and gold from electronic industrial wastewater
}

Quoc An Trieu, S Pellet-Rostaing, Guilhem Arrachart, Y. Traore, S. Kimbel, S. Daniele

\section{To cite this version:}

Quoc An Trieu, S Pellet-Rostaing, Guilhem Arrachart, Y. Traore, S. Kimbel, et al.. Interfacial study of surface-modified $\mathrm{ZrO} 2$ nanoparticles with thioctic acid for the selective recovery of palladium and gold from electronic industrial wastewater. Separation and Purification Technology, 2020, 237, pp.116353. 10.1016/j.seppur.2019.116353 . hal-02551702

\section{HAL Id: hal-02551702 \\ https://hal.science/hal-02551702}

Submitted on 25 Oct 2021

HAL is a multi-disciplinary open access archive for the deposit and dissemination of scientific research documents, whether they are published or not. The documents may come from teaching and research institutions in France or abroad, or from public or private research centers.
L'archive ouverte pluridisciplinaire HAL, est destinée au dépôt et à la diffusion de documents scientifiques de niveau recherche, publiés ou non, émanant des établissements d'enseignement et de recherche français ou étrangers, des laboratoires publics ou privés. 


\section{Interfacial study of surface-modified $\mathrm{ZrO}_{2}$ nanoparticles with thiotic acid for the selective recovery of palladium and gold from electronic industrial wastewater}

Quoc An TRIEU ${ }^{1}$, Stéphane PELLET-ROSTAING ${ }^{2}$, Guilhem ARRACHART ${ }^{2}$, Youssouf TRAORE ${ }^{3}$, Serge KIMBEL ${ }^{3}$, Stéphane DANIELE ${ }^{1 * \S}$

${ }^{1}$ Université de Lyon, IRCELYON-UMR 5256, 69626 Villeurbanne cedex, France

${ }^{2}$ ICSM, CEA, CNRS, ENSCM, Univ Montpellier, Marcoule, France

${ }^{3}$ Morphosis, 576 Boulevard Jules Durand, 76600 Le Havre, France 


\section{ABSTRACTS}

The stability and performance of surface-modified zirconia nanoparticles with thioctic acid to effectively and selectively capture Pd(II) and $\mathrm{Au}(\mathrm{III})$ ions from industrial electronic waste water were investigated. A particular interest laid in the robustness of the interface in highly acidic and oxidizing environments under real conditions. Surface modifications of commercial nano- $\mathrm{ZrO}_{2}$ were optimized from Brønsted acid-base surface reactions in aqueous solution, either by direct thioctic acid (TOA) grafting or by a two-step process: (i) alendronic acid (AA) grafting and (ii) amide coupling reaction between $\mathrm{AA}$ and TOA, giving inorganic-organic hybrid systems designated respectively as $\mathrm{ZrO}_{2}$-TOA and $\mathrm{ZrO}_{2}-\mathrm{AA}-\mathrm{TOA}$. All materials were thoroughly characterized and had a similar specific surface area $\left(50 \mathrm{~m}^{2} \cdot \mathrm{g}^{-1}\right)$. They also demonstrated similar characteristics in terms of thermodynamic and kinetic adsorption data (Langmuir adsorption model and pseudo-second order model). The ATR-FTIR, DRIFT-FTIR and ${ }^{31} \mathrm{P}$ solid state NMR data elucidated the bidentate bridging and tripodal bonding modes for TOA and AA coordination, respectively. In addition, the DRIFT technique was used to reveal the covalent amide bond between the $-\mathrm{NH}_{2}$ group of the AA group and the -COOH groups of the TOA. The adsorption capacities of $\mathrm{ZrO}_{2}$-TOA at $\mathrm{Pd}$ and $\mathrm{Au}$ of $44.6 \mathrm{mg} / \mathrm{g}$ and $6.3 \mathrm{mg} / \mathrm{g}$ respectively, showed that our systems had competitive adsorption capacities and selectivity compared to the literature. Nevertheless, $\mathrm{ZrO}_{2}$-TOA was too sensitive to hydrolysis in high acid concentration ([HCl] $\left.>1 \mathrm{M}\right)$ and the use of $\mathrm{ZrO}_{2}$-AA-TOA was then mandatory to overcome hydrolytic cleavage of M-OOC bonds in media with high acid concentration. The novel $\mathrm{ZrO}_{2}$-AA-TOA material demonstrated promising stability, efficiency and reusability in industrial applications for gold and palladium recovery.

Keywords: Thioctic acid; alendronic acid; gold and palladium recoveries; e-waste 


\section{INTRODUCTION}

Precious metals, in particular palladium (Pd) from PGMs (platinum group metals) and gold (Au), have been commonly used in many different industrial applications, such as jewellery, catalysts and high-tech devices, due to their high conductivity and anti-corrosion properties. Because of the amount of end-of-life of electrical and electronic equipment, called waste electrical and electronic equipment (WEEE) or e-waste, processed annually, it represents a suitable alternative resource for valuable metals from sources other than ores. From an economic point of view, the mining and extraction of gold and/or palladium would no longer be profitable and sustainable compared to the recycling of e-waste ${ }^{1}$. As a result, e-waste has been considered as an "urban mine", due to its increasing value. According to a recent survey, 44.7 million tons of e-waste were produced in 2016 and the value of raw materials contained in e-waste was estimated at around $€ 55$ billion ${ }^{2}$. The medals for the 2020 Olympic Games in Japan will be made entirely of the metal of millions of recycled devices (mainly telephones). The collection lasted two years and 28 kilos of gold and more than 5,000 kilos of silver and bronze were collected to make the 5,000 medals that will be awarded during the Games.

After collection, e-waste is subjected to different stages of the recycling process during which preliminary physical processes, such as disassembly, shredding, classification and separation, are used. Subsequently, the fraction containing the metal is involved in metallurgical steps using different types of metal leaching agents, such as aqua regia, thiourea, thiosulfate, etc. ${ }^{3}$ Purification and separation processes play a crucial role in the overall process to increase the purity of the final product. Various hydrometallurgical technologies have been studied to improve this process, such as electrolysis, precipitation, solvent extraction and solid-liquid adsorption. When it comes to profitability, ease of use and environmental benefits, processes using solid-liquid adsorption appear to be predominant options. For palladium and gold separation/purification, two types of commercial adsorbents were used with different mechanisms: (i) ion exchange, including Bonlite BA304, Purolite A500 ${ }^{4}$ strong base resins or Dowex Marathon WBA, Diaion WA21J ${ }^{5}$ weak base resins and (ii) coordination process based on adsorbents bearing functional groups containing $\mathrm{N}$ and S atoms, e. g. Duolite GT-73 6 or synthetic chelate resins functionalized with amine, thio, amine/mercaptan groups ${ }^{7}$. J. M. Sánchez et al. demonstrated better adsorption of chelating polymers containing phosphine sulfide $(\mathrm{P}=\mathrm{S})$ on commercial quaternary ammonium resins 
(Amberlite IRA 410 and 910) in terms of performance and selectivity ${ }^{8}$. Among these materials, phosphine-oxide resins have demonstrated high adsorption performance to PGMs ( $\mathrm{Pt}, \mathrm{Pd}, \mathrm{Rh}$ ) in an aqueous solution containing abundant competing ions, having a low $\mathrm{pH}$ and carrying an oxidizing aqua regia nitrate anion ${ }^{9}$. Effluents from recycling plants usually contain traces of $\mathrm{Pd}$ and $\mathrm{Au}$ in the concentration range of 10 to $100 \mathrm{ppm}$, competing major ions, highly acidic and oxidizing media; therefore, the value of the effluents will only be able to contribute significantly to recycling processes if cost-effective methods or materials are readily available to capture these metals.

In addition to polymeric adsorbents, nano-adsorbents based on nanometallic oxide are of increasing interest due to their high surface-to-volume ratio. In addition, the presence of a surface modification of the inorganic support is likely to confer synergistic selectivity properties on the hybrid material resulting from it. The adjustment of inorganic supports by surface modification was carried out using many reagents called "coupling agents" or "anchoring molecules" such as silanes (RxSiX4-x, $x=0,1,1,2,3$ ), amines, phosphonates (phosphonic acid, $\mathrm{RP}(\mathrm{O})(\mathrm{OH}) 2$ or phosphonate ester derivatives, $\left.\mathrm{RP}(\mathrm{O})(\mathrm{OR})_{2}\right)^{10}$, carboxylic acids and others ${ }^{11}$.

Few reports have shown that phosphonates are of particular interest in obtaining an effective, robust and controllable monolayer on the surface of oxide substrates. Previously, our group has demonstrated the ability of nano- $\mathrm{TiO}_{2}$ materials modified on the surface by different monophosphonate molecules as effective and selective nano-adsorbents to light or heavy polyaromatic hydrocarbons (PAH) ${ }^{12}$. With regard to the nature of the support for metal adsorption applications ${ }^{13}$, nano-zirconium oxide $\left(\mathrm{ZrO}_{2}\right)$ has also gained a lot of interest due to the high chemical stability of Zr-O-P which has extended its application to some difficult matrices that are very rich in acidity, oxidizing power and complexity ${ }^{14}$. V. Luca et al. have demonstrated that a combination of polyphosphonate ligands (such as alendronate) and Zr-rich carrier compositions has resulted in hybrid materials that can be used in nuclear applications where acid stability is crucial ${ }^{15}$.

We present here the influence of the interface of zirconia-based materials, modified on the surface by carboxylate or polyphosphonate ligands, as effective and robust nano-adsorbents for extracting $\mathrm{Pd}$ and $\mathrm{Au}$ from WEEE wastewater recycling processes. Commercial $\mathrm{ZrO}_{2}$ nanoparticles surface modified with thioctic acid (TOA) by a one- or two-step functionalization process, consisting of (i) surface modification with alendronic acid (AA) and (ii) covalent grafting of AA with a TOA 
group by amide coupling reactions have been fully characterized and their performance as nanoadsorbents compared. This work highlights the effect of the nature of the grafting groups which affects the stability of the resulting materials and ultimately their properties and recyclability. This contribution will focus on the development and applications of hybrid nanomaterials for the effective absorption of traces of Pd and Au ions from real industrial wastewater effluents.

\section{EXPERIMENTAL SECTION}

\subsection{Reagents and Chemicals}

All chemicals were of analytical grade and used without further purification. DL-Thioctic acid (TOA) (> 98\%, $\mathrm{C}_{8} \mathrm{H}_{14} \mathrm{O}_{2} \mathrm{~S}_{2}, \mathrm{M}_{\mathrm{w}}=206.32 \mathrm{~g} / \mathrm{mol}$ ) and Alendronic Acid (AA) (> 98\%, $\mathrm{C}_{4} \mathrm{H}_{13} \mathrm{NO}_{7} \mathrm{P}_{2}$, $\mathrm{M}_{\mathrm{w}}=249.1 \mathrm{~g} / \mathrm{mol}$ ) were purchased from ACROS Organics ${ }^{\mathrm{TM}}$. N, N' - Dicyclohexylcarbodiimide (DCC) $\left(>99 \%, \mathrm{C}_{6} \mathrm{H}_{11} \mathrm{~N}=\mathrm{C}=\mathrm{NC}_{6} \mathrm{H}_{11}, \mathrm{M}_{\mathrm{w}}=206.33 \mathrm{~g} / \mathrm{mol}\right)$, anhydrous ethanol $\left(\mathrm{C}_{2} \mathrm{H}_{5} \mathrm{OH}\right.$, ACS reagent, 99\%) and hydrochloric acid ( $\mathrm{HCl}$, ACS reagent, fuming, $\geq 37 \%$ ) were purchased from Sigma-Aldrich. Sodium chloride (ACS reagent) was purchased from Carlo Erba. Nhydroxysuccinimide NHS-activated ester of TOA (NHS-TOA) was synthesized and provided by ICSM Institute. $\mathrm{ZrO}_{2}$ nanosuspension (10 wt. \% in $\mathrm{H}_{2} \mathrm{O}, \mathrm{pH} 4-5, \mathrm{~d}_{\mathrm{p}}<100 \mathrm{~nm}$ ) and standard solutions of $\mathrm{Pd}^{2+}\left(9373 \mathrm{mg} \mathrm{kg}^{-1} \pm 20 \mathrm{mg} \mathrm{kg}^{-1}\right.$ in $10 \% \mathrm{HCl}$, TraceCERT $\left.{ }^{\circledR}\right)$ and $\mathrm{Au}^{3+}\left(975 \mathrm{mg} \mathrm{kg}^{-1} \pm\right.$ $2 \mathrm{mg} \mathrm{kg}^{-1}$ in 5\%) were purchased from Sigma-Aldrich. All solutions were prepared using deionized $18 \mathrm{M} \Omega . c m$ water.

\subsection{Equipment and characterization}

Surface-modified nano-zirconia materials were characterized using attenuated total reflection FTIR (ATR) on Thermo scientific system (model Nicolet Avatar 380) equipped with Diamond crystal (working range: $30000-200 \mathrm{~cm}^{-1}$ ) and diffuse reflectance FTIR (DRIFT) on Nicolet 6700. The determinations of organic content on the $\mathrm{ZrO}_{2}$ 's surface were carried out using TGA/DSC 1 STAR $^{\mathrm{e}}$ system from Mettler Toledo in crucibles alumina $70 \mu \mathrm{L}$. The experiments were recorded under air and were heated from $25^{\circ} \mathrm{C}$ to $900^{\circ} \mathrm{C}$ at rate of $10^{\circ} \mathrm{C}$. $\mathrm{min}^{-1}$. AVANCE III 500WB NMR system with MAS technique was employed to obtain ${ }^{31} \mathrm{P}$ solid-state NMR spectra of zirconia modified with phosphonic acid derivatives. Solid state MAS (Magic Angle Spinning) ${ }^{31} \mathrm{P}$ NMR spectra were recorded using frequency of $202.418 \mathrm{MHz}$, at rotation speed of $10 \mathrm{KHz}$. All measurements used $\mathrm{H}_{3} \mathrm{PO}_{4} 85 \%$ as a reference. Specific surface areas of materials were determined 
using the Micrometrics ASAP 2020 system based on the BET method. Prior to measurements, solids were desorbed at $423 \mathrm{~K}$ for $3 \mathrm{hrs}$. Elemental analyses determining the concentrations of Pd, $\mathrm{Au}, \mathrm{Cu}, \mathrm{Ni}$, and Fe were conducted based on the ICP-OES system ACTIVA from HORIBA. Regarding liquid samples, direct determinations were carried out at suitable emission lines (Pd at 340.46, 324.27 nm; Au at 242.79, $267.27 \mathrm{~nm}, \mathrm{Cu}$ at 224.70, $327.39 \mathrm{~nm}, \mathrm{Ni}$ at 221.65, 230.30, $231.60 \mathrm{~nm}$ and Fe at 240.49, $259.94 \mathrm{~nm}$ ). With respect to solid samples comprising modifiedzirconia nanoparticles, samples were decomposed at $250-300^{\circ} \mathrm{C}$ in the mixture of $\mathrm{H}_{2} \mathrm{SO}_{4}$ and $\mathrm{HNO}_{3}$ (for powder) until the white fume of $\mathrm{SO}_{3}$ starts to appear, dilute with water and evaporate until dryness. Eventually, the residue was dissolved in $\mathrm{HNO}_{3} 1 \%$.

\subsection{Procedures for adsorption and stripping experiment}

Batch adsorption experiments were used to evaluate and compare the adsorption capacity and selectivity of thioctic acid-modified zirconia samples. This method was also used to study the effect of parameters of the thioctic acid-modified zirconia adsorption process such as time contact, $\mathrm{HCl}$ concentration and stripping process. Unless otherwise indicated, the experiments were performed by adding $50 \mathrm{mg}$ of hybrid nanomaterial in $20 \mathrm{~mL}$ of a solution containing Pd and/or $\mathrm{Au}$ at a defined initial concentration $(\mathrm{Ci})$ and then stirring the mixture for a specified period (t). Finally, the supernatant solution was separated by centrifugation at $4000 \mathrm{rpm}$ and the concentration of Pd and/or Au (Cf) was determined by the ICP-OES technique. The extraction percentage E (\%) to Pd and/or Au has been calculated as follows:

$$
E(\%)=\frac{\left(C_{f}-C_{i}\right)}{C_{i}} \times 100 \%
$$

Batch experiments were performed to investigate the adsorption capacities of $\mathrm{Pd}$ and $\mathrm{Au}$ and the adsorption isotherm of $\mathrm{Pd}$ and $\mathrm{Au}$, but series of batch experiments were performed in which the initial concentrations of Pd or Au varied between 5 and $300 \mathrm{mg} / \mathrm{L}$. The equilibrium adsorption capacity q (mg/g) was calculated according to the following formula:

$$
q\left(\frac{m g}{g}\right)=\frac{\left(C_{f}-C_{i}\right) \times V}{m}
$$


In the desorption and recyclability study of the nanomaterials $\mathrm{ZrO}_{2}$-TOA and $\mathrm{ZrO}_{2}-\mathrm{AA}-\mathrm{TOA}$, Pd was extracted by a mixture of $0.2 \mathrm{M}$ thiourea and $0.5 \mathrm{M} \mathrm{HCl}$ from the material loaded with Pd after adsorption in the previous step (20 mL Pd solution $10 \mathrm{mg} \cdot \mathrm{kg}^{-1}$ ). In a typical experiment, 50 mg of $\mathrm{ZrO}_{2}$-TOA or $\mathrm{ZrO}_{2}$-AA-TOA loaded with Pd were separated from the medium, washed with water (2 x $20 \mathrm{~mL})$ and shaken with $10 \mathrm{~mL}$ of $0.2 \mathrm{M}$ thiourea and $0.5 \mathrm{M} \mathrm{HCl}$ for 4 hours. The materials were then washed with water ( 2 x $15 \mathrm{~mL})$ and reused in another adsorption step.

\subsection{Synthesis of surface modified nano- $\mathrm{ZrO}_{2}$ by thioctic acid (TOA)}

\subsection{1) Direct TOA surface modification process}

In a typical experiment, $6 \mathrm{~mL}$ of a $10 \%$ by weight aqueous solution of a $\mathrm{ZrO}_{2}$ nanosuspension (5 mmol of $\mathrm{ZrO}_{2}$ ) at $\mathrm{pH} 4-5$ was added to a $10 \mathrm{~mL}$ round bottom flask. A solution containing a different amount of TOA dissolved in ethanol was added dropwise to the $\mathrm{ZrO}_{2}$ nanosuspension and the mixture was stirred for 24 hours at $25^{\circ} \mathrm{C}$. The molar ratio $\mathrm{ZrO}_{2} / \mathrm{TOA}$ ranged from 100:1 to 5:1. The solid phase was separated by centrifugation for 10 minutes at $10,000 \mathrm{rpm}$. The supernatant was removed and the solid phase was dispersed in $20 \mathrm{~mL}$ of water, sonicated and then separated by centrifugation. The washing procedure was repeated twice with water $(2 \times 20 \mathrm{~mL})$ and three times with ethanol (3x20 mL). The hybrid zirconia powder was dried at $80^{\circ} \mathrm{C}$ for 24 hours.

\subsection{2) Two-step surface modification process}

$1^{\text {st }}$ step - surface functionalization with alendronic acid (AA): $8 \mathrm{~g}$ of $10 \%$ by weight water $\mathrm{ZrO}_{2}$ nanosuspension (6.5 mmol of $\mathrm{ZrO}_{2}$ ) was stirred in $10 \mathrm{~mL}$ of $10^{-1} \mathrm{M}$ AA solution ( $1 \mathrm{mmol}$ of AA) and refluxed for 4 hours. The powder obtained was washed three times with water ( 3 x 10 $\mathrm{mL}$ ) and dried for 24 hours at $80^{\circ} \mathrm{C}$

$2^{\text {nd }}$ step - amide coupling reaction with thioctic acid (TOA):

Path A- using NHS-activated ester of TOA (NHS-TOA): To $0.20 \mathrm{~g}$ of $\mathrm{ZrO}_{2}$-AA was added 2 $\mathrm{mL}$ of NHS-TOA reagent and the mixture was stirred for $24 \mathrm{hrs}$ at $25^{\circ} \mathrm{C}$. The powder was separated by centrifugation for $10 \mathrm{~min}$ at 10,000 rpm and washed three times with DMF (3x15 $\mathrm{mL})$ and three times with ethanol $(3 \times 15 \mathrm{~mL})$. The white powder $\mathrm{ZrO}_{2}$-AA-TOA was dried at $80^{\circ} \mathrm{C}$ for 24 hrs.

Path B- using TOA mediated by DCC (TOA/DCC): $0.10 \mathrm{~g}$ of TOA (0.48 mmol) and $0.15 \mathrm{~g}$ of DCC $(0.73 \mathrm{mmol})$ were mixed in $5 \mathrm{~mL}$ of anhydrous $\mathrm{C}_{2} \mathrm{H}_{5} \mathrm{OH}$ and then the mixture was stirred 
for $30 \mathrm{~min}$. The resultant solution was filtered through $0.45 \mu \mathrm{m}$ filter to remove any precipitate and $0.30 \mathrm{~g}$ of $\mathrm{ZrO}_{2}$-AA was poured into. The mixture was stirred for $24 \mathrm{hrs}$ at $25^{\circ} \mathrm{C}$ and the powder was separated via centrifugation for $10 \mathrm{~min}$ at 10,000 rpm and washed three times with ethanol $(3 \times 15 \mathrm{~mL})$. The white powder $\mathrm{ZrO}_{2}$-AA-TOA was dried at $80^{\circ} \mathrm{C}$ for $24 \mathrm{hrs}$.

All samples were manually crushed by pestle and mortar to desaglomerate them before use.

\section{RESULTS AND DISCUSSION}

\subsection{Syntheses of hybrid $\mathrm{ZrO}_{2}$ nano-absorbents}

The surface modifications of commercial nano- $\mathrm{ZrO}_{2}$ were based on acid-base Brønsted surface reactions in aqueous solution at $25^{\circ} \mathrm{C}$ for 24 hours, either by direct thioctic acid (TOA) grafting or by a two-step route: (i) alendronic acid (AA) grafting and (ii) amide coupling reaction between AA and TOA; obtaining inorganic-organic hybrid systems (in the form of white powders) and designated respectively by $\mathrm{ZrO}_{2}$-TOA and $\mathrm{ZrO}_{2}$-AA-TOA, respectively (Figure 1). The $\mathrm{pH}$ has been set around 4-5 to be far from the zero point of charge of our $\mathrm{ZrO}_{2}$ support (around 9) to avoid any aggregation of the support. It should be noted that all our attempts of direct coupling reactions between alendronic acid and thioctic acid even with activated thioctic acid such as NHS-TOA have been unsuccessful. 


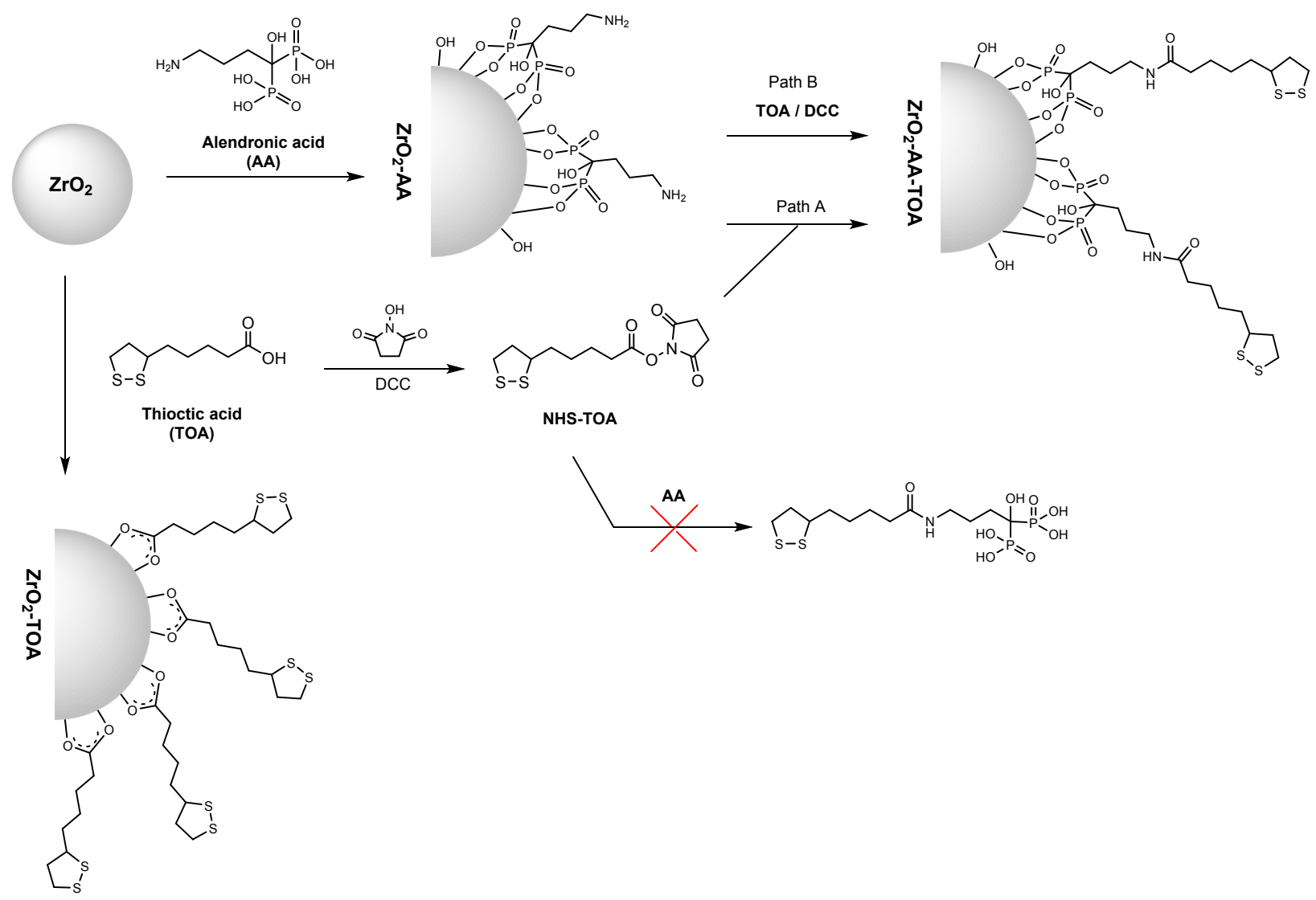

Figure 1. Schematic illustration of $\mathrm{ZrO}_{2}-\mathrm{TOA}$ and $\mathrm{ZrO}_{2}-\mathrm{AA}$-TOA hybrid nanomaterials studied (nano $\mathrm{ZrO}_{2}$ support is represented as grey sphere / half sphere)

\subsection{Characterization of $\mathrm{ZrO}_{2}$ nano-hybrids}

The XRD powder diffractograms and TEM images of all $\mathrm{ZrO}_{2}$ nano-hybrids were similar to those of commercial $\mathrm{ZrO}_{2}$, showing a mixture of tetragonal ( 58\%) and monoclinic ( 42\%) $\mathrm{ZrO}_{2}$ (Figure S1) and that the samples are rather polydispersed in size (20 $\pm 10 \mathrm{~nm}$ ) (Figure S2), respectively. These data indicate that our grafting process did not modify the morphology and structure of the $\mathrm{ZrO}_{2}$ starting support.

This was also confirmed from the BET analysis which provides similar specific surface area for all the materials ( $\sim 50 \mathrm{~m}^{2} / \mathrm{g}$ ) (Table 1). Even after the functionalization, the crucial surface area is preserve, which is beneficial for the adsorption application. 
Table 1. Specific surface areas of surface-modified $\mathrm{ZrO}_{2}$ materials determined by BET method

\begin{tabular}{|c|c|}
\hline Material & BET specific surface area $\left(\mathbf{m}^{2} / \mathbf{g}\right)$ \\
\hline $\mathrm{ZrO}_{2}$ & $52.0 \pm 1.0$ \\
\hline $\mathrm{ZrO}_{2}$-TOA & $50.7 \pm 1.7$ \\
\hline $\mathrm{ZrO}_{2}$-AA & $47.5 \pm 1.1$ \\
\hline $\mathrm{ZrO}_{2}$-AA-TOA (NHS-TOA) & $51.2 \pm 1.4$ \\
\hline $\mathrm{ZrO}_{2}$-AA-TOA (TOA-DCC) & $58.0 \pm 1.4$ \\
\hline
\end{tabular}

The weight losses given by the TG analysis, between 160 and $900^{\circ} \mathrm{C}$, were used to estimate the organic fraction in order to maximize it. By performing the one-step TOA surface modification process in the molar ratio range of $\mathrm{ZrO}_{2} / \mathrm{TOA}$ from 100 to 5, a maximum TOA load of about 2.7\% by weight $(0.131 \mathrm{mmol} / \mathrm{g})$ corresponding to an initial $\mathrm{ZrO}_{2} / \mathrm{TOA}$ molar ratio of $50-60$ was obtained. In the case of the modification of the AA surface area, the maximum AA load was approximately $1.8 \%$ by weight. ( $0.073 \mathrm{mmol} / \mathrm{g}$ ) for an initial molar ratio $\mathrm{ZrO}_{2} / \mathrm{AA}$ of $6-7$. It should be noted that this value is largely underestimated because phosphate residues were still present after calcination at $900^{\circ} \mathrm{C}$ (as shown by solid state ${ }^{31} \mathrm{P}$ NMR data, Figure S3) which contributed to the apparent weight of the inorganic fraction. Nevertheless, the estimated grafting densities for the $\mathrm{ZrO}_{2}$-TOA and $\mathrm{ZrO}_{2}$-AA samples, obtained from TGA (TGA) data and using equation eq. 1 , gave $1.58 \mathrm{TOA} / \mathrm{nm}^{2}$ and $0.87 \mathrm{AA} / \mathrm{nm}^{2}$, respectively. An elemental phosphorus analysis was also performed for the $\mathrm{ZrO}_{2}$-AA sample to obtain $2.23 \%$ by weight of organic fraction, resulting in an estimated grafting density of $1.06 \mathrm{AA} / \mathrm{nm}^{2}$ for $\mathrm{ZrO}_{2}-\mathrm{AA}$. This value is in accordance with the literature assuming $24 \AA^{2}$ per phosphonic group and a coverage not exceeding a monolayer ${ }^{16}$.

$$
\sigma_{\mathrm{TGA}}=(\% \mathrm{wtL} \times \mathrm{Na}) /\left(\mathrm{MW} \times \mathrm{S} \times 10^{18}\right)
$$

Amide coupling reactions performed using either TOA activated with an N-hydroxysuccinimideactivated TOA ester (path A) or N,N-dicyclohexylcarbodiimide (DCC) (path B) resulted in similar final weight losses between 160 and $800^{\circ} \mathrm{C}$ of about $2.8 \%$ by weight $(0.064 \mathrm{mmol} / \mathrm{g})$ and $2.7 \%$ by 
weight $(0.062 \mathrm{mmol} / \mathrm{g})$, respectively (Figure 2$)$. Therefore, the reaction yields along these two routes were estimated in a comparable way to about $88 \%$ (theoretical weight loss of 3.2\%).

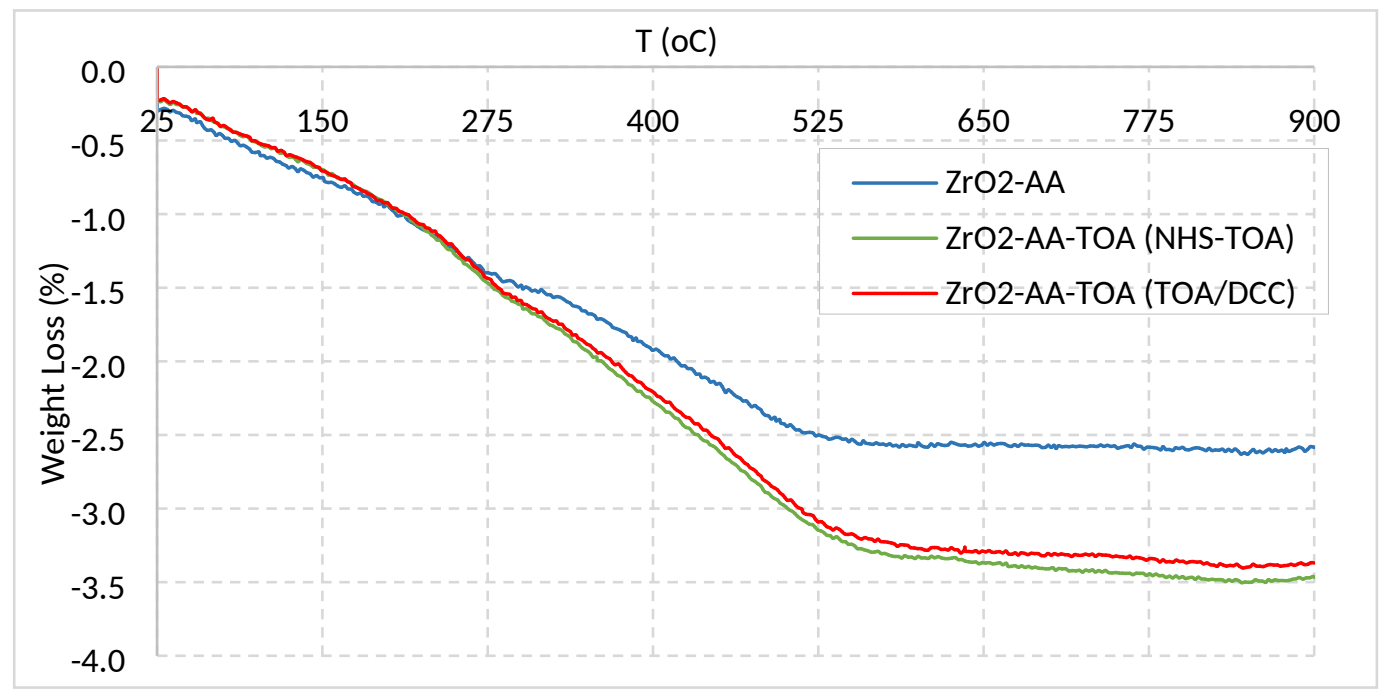

Figure 2. TGA curves of $\mathrm{ZrO}_{2}$-AA and $\mathrm{ZrO}_{2}$-AA-TOA (NHS-TOA) and $\mathrm{ZrO}_{2}$-AA-TOA (TOA/DCC) samples

ATR-FTIR spectroscopy was first used to detect the presence of ligands and retrieve relevant information on the nature of carboxylic and phosphonic acid bonds on the surface of $\mathrm{ZrO}_{2}$. The ATR-FTIR spectrum of $\mathrm{ZrO}_{2}$-TOA displayed new absorption bands at $1559 \mathrm{~cm}^{-1}$ and 1435 $\mathrm{cm}^{-1}$ corresponding to asymmetric and symmetric $\mathrm{CO}_{2}^{-}$stretching bands, respectively (Figure S4). The value $\Delta v=\left[\operatorname{vas}\left(\mathrm{CO}_{2}^{-}\right)-\operatorname{vs}\left(\mathrm{CO}_{2}^{-}\right)\right]=124 \mathrm{~cm}^{-1}$ was compatible with the expected bidentate/chelating coordination ${ }^{17}$. The absorption band associated with the methylene chains was located at about $2935 \mathrm{~cm}^{-1}$ and the free TOA band at about $1690 \mathrm{~cm}^{-1}$ was not present. $\mathrm{ZrO}_{2}$-AA was also characterized by ATR-FTIR and its spectrum showed the presence of AA phosphonate groups $\left(-\mathrm{PO}_{3}\right.$ ) on the surface of $\mathrm{ZrO}_{2}$ due to the wide absorption bands at 1130 and $993 \mathrm{~cm}^{-1}$ (Figure S5). Tridentate bonds are likely due to the disappearance of the $\mathrm{P}=\mathrm{O}$ and $\mathrm{P}-\mathrm{OH}$ stretching bands at 1200 and $917 \mathrm{~cm}^{-1}$, respectively. In an attempt to confirm the amide coupling between the primary amine group of the AA group and the carboxylic group of the TOA, the DRIFT technique was used to collect spectra with higher sensitivity and resolution that can reduce the interference effect of water bands ( 3400 and $1630 \mathrm{~cm}^{-1}$ ) in the region from $1400 \mathrm{~cm}^{-1}$ to $1700 \mathrm{~cm}^{-1} 18$.

DRIFT spectra $\left(25^{\circ} \mathrm{C}\right)$ have also confirmed phosphonate grafts with a high absorption band at about $1200 \mathrm{~cm}^{-1}$ (Figure3). The overlap between the water bending bands at $\sim 1674 \mathrm{~cm}^{-1}$ and the 
amide bands [ $\left.v(\mathrm{C}=\mathrm{O})=1600-1700 \mathrm{~cm}^{-1}\right]$ was confirmed by recording the spectra after desorption of the water at $105^{\circ} \mathrm{C}$ for 24 hours under vacuum (Figure 4), showing a decrease in band intensity at $\sim 3400$ and $\sim 1630 \mathrm{~cm}^{-1}$ in both spectra of the $\mathrm{ZrO}_{2}$-AAA and $\mathrm{ZrO}_{2}$-AA-TOA samples. Thus, the residual signal at $1630 \mathrm{~cm}^{-1}$ in the $\mathrm{ZrO}_{2}$-AA spectrum was assigned to the -OH group in the AA structure. In addition, the intensity of the band at $\sim 1630 \mathrm{~cm}^{-1}$ in the $\mathrm{ZrO}_{2}-\mathrm{AA}-\mathrm{TOA}$ spectra was higher than that of the $\mathrm{ZrO}-\mathrm{AA}$ spectrum resulting from the contribution of amide (mainly $\mathrm{C}=\mathrm{O}$ stretching band) created between - $\mathrm{NH}_{2}$ group of $\mathrm{AA}$ and -COOH group of TOA.

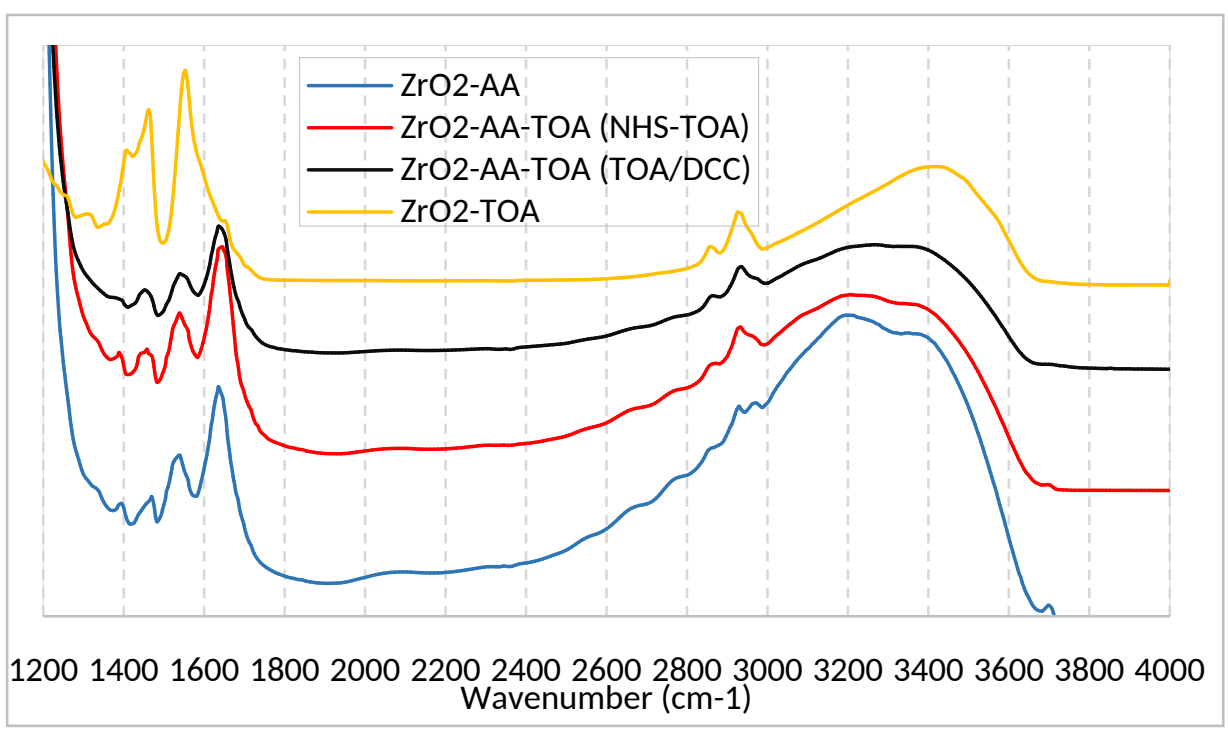

Figure3. DRIFT spectra of $\mathrm{ZrO}_{2}$-AA, $\mathrm{ZrO}_{2}$-AA-TOA (NHS-TOA), $\mathrm{ZrO}_{2}$-AA-TOA (TOA/DCC) and $\mathrm{ZrO}_{2}$-TOA. 


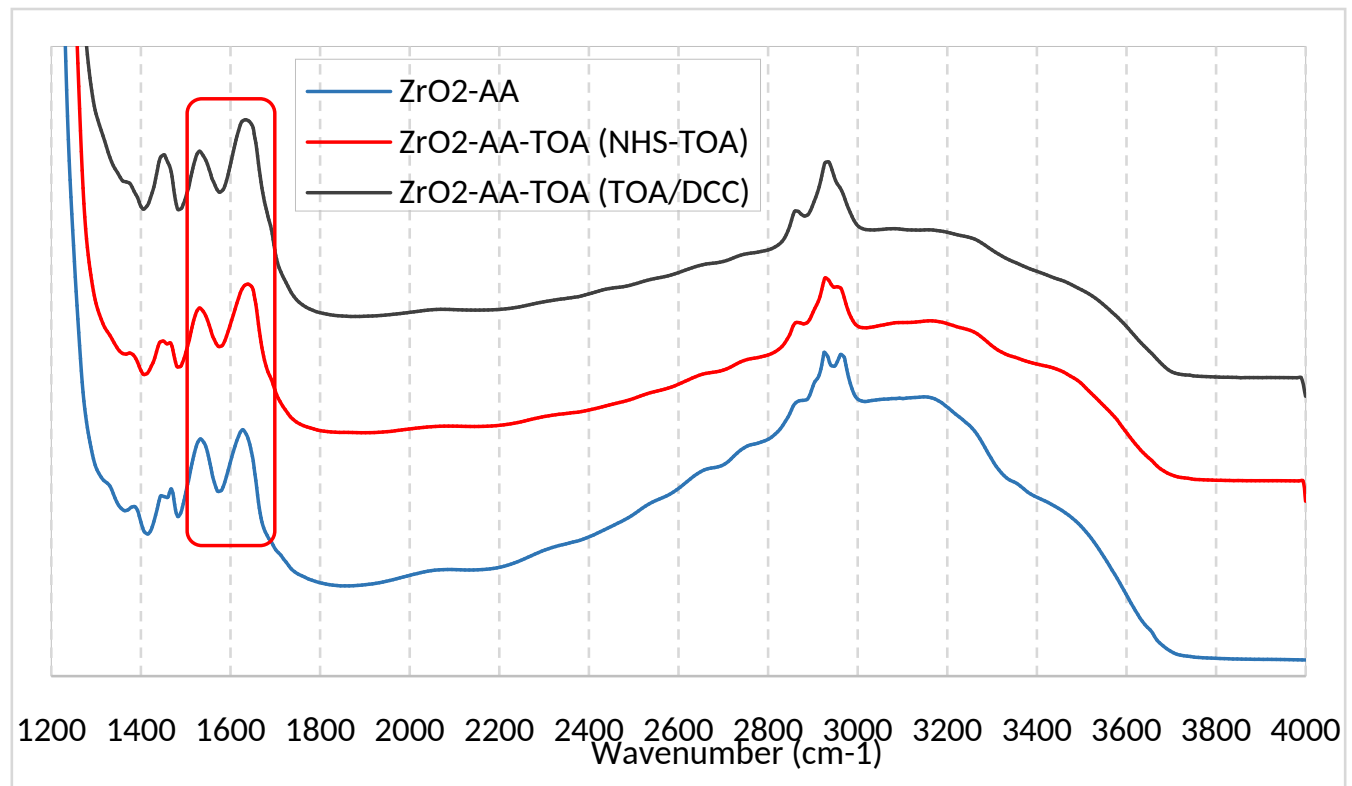

Figure 4. DRIFT spectra of $\mathrm{ZrO}_{2}-\mathrm{AA}, \mathrm{ZrO}_{2}$-AA-TOA samples after water desorption at $105^{\circ} \mathrm{C}$

Many publications have reported the use of ${ }^{31} \mathrm{P}$ solid state NMR for the characterization of nano-metallic oxides modified with phosphonic acids in which different species such as physisorbed and/or chemisorbed phosphonate could be distinguished ${ }^{19}$. AA is a biphosphonic acid existing in zwitterionic form which contains a neutral $-\mathrm{P}(\mathrm{O})(\mathrm{OH})_{2}$ and an anionic $-\mathrm{P}(\mathrm{O})(\mathrm{O}-)(\mathrm{OH})$ group ${ }^{20}$. As a result, the ${ }^{31} \mathrm{P}$ solid state NMR spectrum had two resonance peaks at $22.7 \mathrm{ppm}$ and $13.0 \mathrm{ppm}$ with a very narrow width, respectively. The solid state ${ }^{31} \mathrm{P} \mathrm{NMR}$ spectra of $\mathrm{ZrO}_{2}-\mathrm{AA}$ and $\mathrm{ZrO}_{2}$-AA-TOA broadened in a range from -4 to $34 \mathrm{ppm}$ which was characteristic of metal oxides functionalized with phosphonate ligands ${ }^{21}$ (Figure 5). The chemical shifts of ${ }^{31} \mathrm{P}$ NMR were greatly influenced by the surrounding environment, including the length/bond angle O-P-O and the electronegativity of the neighbouring atoms. Therefore, the width of the ${ }^{31} \mathrm{P}$ resonance peak could not be calculated by the MAS technique due to the different binding modes of the phosphonic acid head groups to the surface of $\mathrm{ZrO}_{2}{ }^{19 a}, 22$. A tripodal binding mode was probably present due to the decrease in $\mathrm{P}=\mathrm{O}$ absorbance in the ATR-FTIR spectrum and the widening of the NMR peak. Weak downfield chemical shift of $\mathrm{ZrO}_{2}$-AA-TOA relative to $\mathrm{ZrO}_{2}$-AA could be explained by the presence of an amide bond (-NH-CO) that promoted an electron-withdrawing effect, thus deshielding $\mathrm{P}$ atoms. 


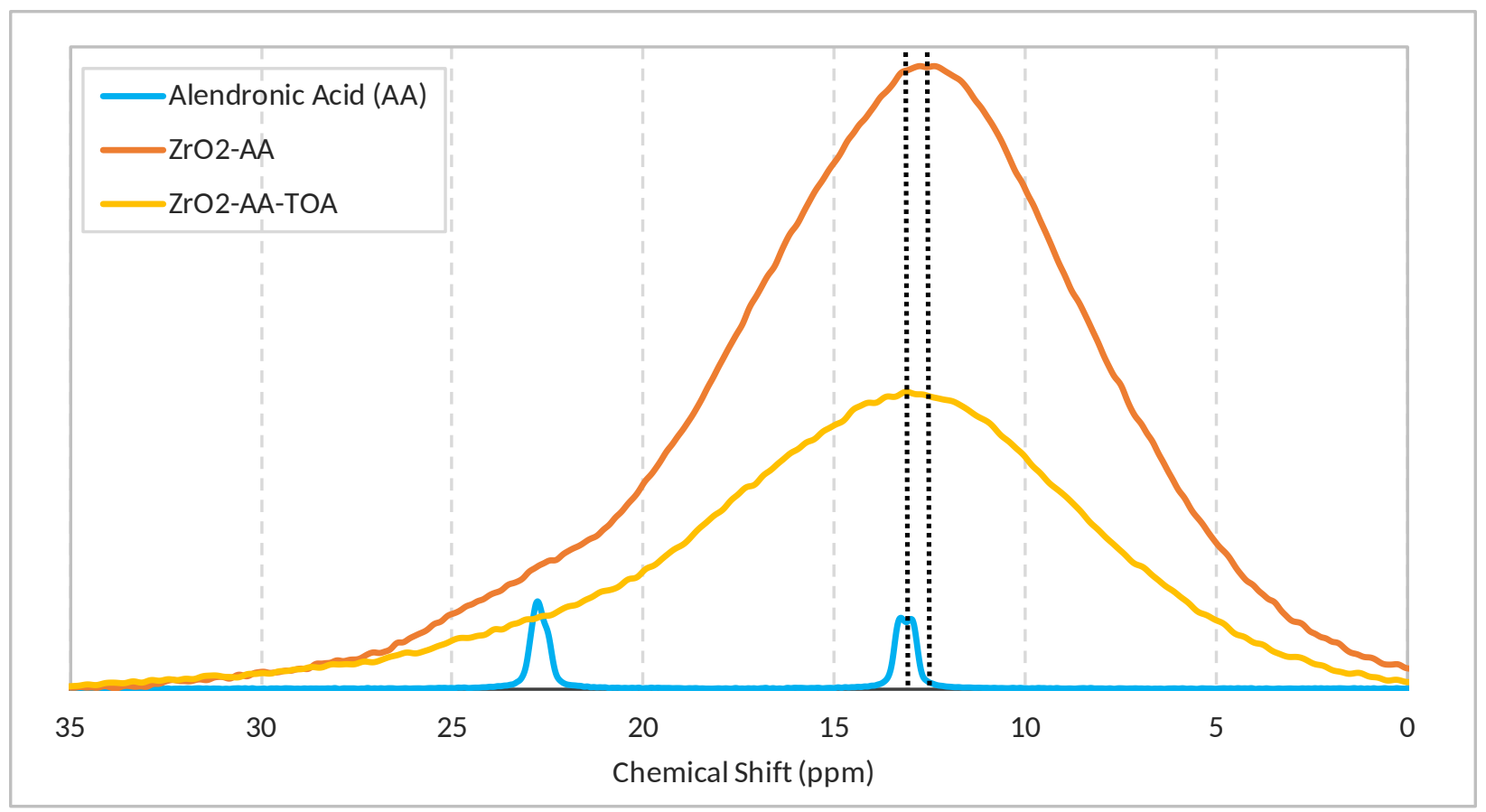

Figure 5. ${ }^{31} \mathrm{P}$ MAS solid-state NMP spectra of Alendronic Acid (AA), $\mathrm{ZrO}_{2}-\mathrm{AA}$, and $\mathrm{ZrO}_{2}-\mathrm{AA}-\mathrm{TOA}$.

\subsection{Palladium and gold adsorption studies}

The two hybrid nanomaterials $\mathrm{ZrO}_{2}$-TOA and $\mathrm{ZrO}_{2}$-AA-TOA with a maximum organic load of about $2.7 \%$ by weight (from TGA) were investigated in Pd and Au adsorption processes.

In adsorption studies, determinations of adsorption capacity or loading capacity, defined as the maximum amount of adsorbate captured by $1 \mathrm{~g}$ of adsorbent at equilibrium state, is of great importance to describe the characteristic of the nano-adsorbent, evaluate and compare the adsorption performance of the nano-adsorbents to the target adsorbates. The main objective of our study was to understand and highlight the effectiveness of TOA as a trapping agent for $\mathrm{Pd}^{2+}$ and $\mathrm{Au}^{3+}$ ions. An article published during our study showed that $\mathrm{Fe}_{3} \mathrm{O}_{4} @ \mathrm{SiO}_{2}$ core-shell nanoparticles functionalized with thioctic acid could be of interest for precious metal recycling, but these systems have not been used to process real industrial solutions at very low $\mathrm{pH}^{23}$. With regard to the study of the reusability of the resulting materials, comparative adsorption and desorption cycles to standard solutions of $\mathrm{Pd}^{2+}$ and/or $\mathrm{Au}^{3+}$ in $\mathrm{HCl}$ and industrial electronic waste water matrices were carried out to demonstrate and highlight the crucial role of the two-step surface modification process in terms of robustness. 
The adsorption capacities of $\mathrm{ZrO}_{2}$-TOA and $\mathrm{ZrO}_{2}-\mathrm{AA}-\mathrm{TOA}$ with $\mathrm{Pd}^{2+}$ and $\mathrm{Au}^{3+}$ were achieved with $50 \mathrm{mg}$ of material and $25 \mathrm{~mL}$ of $25 \mathrm{mg} \mathrm{Pd} / \mathrm{L}$ or $135 \mathrm{mg} \mathrm{Au} / \mathrm{L}$ and the results are summarized in Table 2.

Table 2. $\mathrm{Pd}$ and $\mathrm{Au}$ adsorption capacities summary of $\mathrm{ZrO}_{2}-\mathrm{TOA}$ vs. $\mathrm{ZrO}_{2}-\mathrm{AA}-\mathrm{TOA}$ in standard solutions

\begin{tabular}{|c|c|c|c|c|c|c|c|}
\hline \multirow{2}{*}{ Materials } & \multirow{2}{*}{$\mathbf{n}_{\mathrm{R}-\mathrm{S}-\mathrm{S}-\mathrm{R}}(\boldsymbol{\mu} \mathbf{m o l} / \mathbf{g})$} & \multicolumn{2}{|c|}{$\begin{array}{c}\text { Adsorption } \\
\text { capacity (mg/g) }\end{array}$} & \multicolumn{2}{|c|}{$\mathbf{n}_{\mathrm{M}(\mathbf{a})}(\boldsymbol{\mu m m o l} / \mathbf{g})$} & \multicolumn{2}{|c|}{$\mathbf{n}_{\mathrm{R}-\mathrm{s}-\mathrm{S}-\mathrm{R} / \mathbf{n}_{\mathrm{M}(\mathbf{a})}}$} \\
\cline { 3 - 8 } & & $\mathrm{Pd}$ & $\mathrm{Au}$ & $\mathrm{Pd}$ & $\mathrm{Au}$ & $\mathrm{Pd}$ & $\mathrm{Au}$ \\
\cline { 3 - 8 } & & 6.3 & 44.6 & 59.2 & 218.3 & 2.2 & 0.6 \\
\hline $\mathrm{ZrO}_{2}$-TOA & 131 & 3.5 & 6.4 & 32.9 & 32.5 & 1.9 & 2.0 \\
\hline $\mathrm{ZrO}_{2}$-AA-TOA & 64 & & & & & & \\
\hline
\end{tabular}

The maximum experimental adsorption capacities were determined to be 6.3 and $44.6 \mathrm{mg} / \mathrm{g}$ for $\mathrm{Pd}^{2+}$ and $\mathrm{Au}^{3+}$, respectively, in the same order as in the published comparable studies (Table 3).

Table 3. Adsorption capacities to Au and/or Pd of different adsorbents in previous publications

\begin{tabular}{|c|c|c|c|c|}
\hline \multirow{2}{*}{ Used adsorbents } & \multirow{2}{*}{$\begin{array}{c}\text { Targeted } \\
\text { metals }\end{array}$} & \multicolumn{2}{|c|}{$\begin{array}{c}\text { Capacity } \\
\text { (mg/g) }\end{array}$} & \multirow{2}{*}{ References } \\
\cline { 3 - 4 } & Pd & Au & 24 \\
\hline $\begin{array}{c}\text { Phosphine sulphide-type chelating } \\
\text { polymers }\end{array}$ & $\mathrm{Au}, \mathrm{Pd}$ & 11.7 & 78.8 & 5 \\
\hline Diaion WA21J & $\mathrm{Pd}$ & 4.84 & - & 25 \\
\hline $\begin{array}{c}\text { DTDGA-impregnated XAD-16 Beads } \\
\text { with 2-Acetyl Amide group }\end{array}$ & $\mathrm{Au}$ & - & 35 & 26 \\
\hline $\begin{array}{c}\text { p-tert-butylthia[4]calixaren- } \\
\text { impregnated Amberlite XAD-7 }\end{array}$ & $\mathrm{Pd}$ & 10.1 & - & 27 \\
\hline $\begin{array}{c}\text { Thioctic acid functionalized silica } \\
\text { coated magnetite nanoparticles }\end{array}$ & $\mathrm{Au}$ & - & 38.3 & 23 \\
\hline
\end{tabular}


Considering the molar ratio of TOA/M (M = Au or Pd), values of 1.8 and 0.5 were obtained for TOA/Pd and for TOA/Au respectively, suggesting that two TOA molecules coordinated a $\mathrm{Pd}^{2+}$ ion, while a TOA molecule could form two coordination bonds with two $\mathrm{Au}^{3+}$ ions. Therefore, since the predominant species of $\mathrm{Pd}(\mathrm{II})$, and $\mathrm{Au}(\mathrm{III})$ in the acid solution beyond $\mathrm{pH} 1$ were the anionic chloro species $\mathrm{PdCl}_{4}{ }^{2-}$, and $\mathrm{AuCl}_{4}{ }^{-28}$, the reactions could be presented as follows (assuming square planar geometries around the metal ions):

$$
\begin{aligned}
\mathrm{PdCl}_{4}^{2-}+2 \mathrm{TOA}_{(\mathrm{s})} & \leftrightarrow\left[\mathrm{PdCl}_{2}(\mathrm{TOA})_{2(\mathrm{~s})}\right]+2 \mathrm{Cl}^{-} \\
2 \mathrm{AuCl}_{4}^{-}+\mathrm{TOA}_{(\mathrm{s})} & \leftrightarrow\left[\left(2 \mathrm{AuCl}_{3}\right) \mathrm{TOA}_{(\mathrm{s})}\right]+2 \mathrm{Cl}^{-}
\end{aligned}
$$

Compared to the adsorption capacities of $\mathrm{ZrO}_{2}$-TOA, the nano-absorbent $\mathrm{ZrO}_{2}$-AA-TOA had lower values mainly due to the lower amount of TOA fragments $\left(64 \mu \mathrm{mol} / \mathrm{g}\right.$ on $\mathrm{ZrO}_{2}$-AA-TOA compared to $131 \mu \mathrm{mol} / \mathrm{g}$ on $\mathrm{ZrO}_{2}-\mathrm{TOA}$ ). With regard to the molar ratio of disulfide fraction (R-SS-R) to adsorbed metals, some conclusions can be drawn: (i) a Pd ion forms coordination bonds with 2 R-S-S-R fragments with a single bond to each fragment, regardless of the amount of TOA on the surface of the materials or types of materials $\left(\mathrm{ZrO}_{2}-\mathrm{TOA}\right.$ or $\mathrm{ZrO}_{2}$-AA-TOA); however, (ii) the molar ratio of disulfide to gold is not constant. This latter result could result from the fact that the disulfide fractions could be partially oxidized to sulfoxide, as proposed in reference 13a, in industrial electronic waste water containing a complex mixture of acids and/or oxidizing species such as $\left[\mathrm{AuCl}_{4}\right]^{-}, \mathrm{HNO}_{3} \ldots$ Other parameters, such as $\mathrm{pH}, \mathrm{Cl}^{-}$concentrations, and thermodynamic and kinetic data have been developed to optimize and understand the performance of the $\mathrm{ZrO}_{2}$ TOA and $\mathrm{ZrO}_{2}$-AA-TOA systems.

\subsection{1 $\mathrm{ZrO}_{2}$-TOA nano-absorbent}

Effect of hydrochloric acid ( $\mathrm{HCl}$ ) and chloride concentration

Effluents from recycling plants and refineries often contain various acids at high concentrations because of their use in the dissolution and separation stages. Among them, hydrochloric acid $(\mathrm{HCl})$ is one of the main components; therefore, the effect of $\mathrm{HCl}$ on adsorption has been studied with respect to extraction efficiency. The impact of chloride concentration was also carried out in order to understand the driving force that governs the coordination process. In this experiment, the extraction percentage of a single solution containing $\mathrm{Pd}^{2+}$ and $\mathrm{Au}^{3+}$ at $10 \mathrm{ppm}$ was monitored while 
the $\mathrm{HCl}$ concentration varied from 0.08 to $6 \mathrm{M}$. All other adsorption parameters were similar to those of previous experiments, including $50 \mathrm{mg} \mathrm{ZrO}_{2}$-TOA, $20 \mathrm{~mL}$ solution and 180 minutes of mixing.

Figure 6 shows a decrease in extraction efficiency for the adsorption of $\mathrm{Au}^{3+}$ and $\mathrm{Pd}^{2+}$ when the $\mathrm{HCl}$ concentration exceeds $1 \mathrm{M}$. The percentage of Pd extraction dropped to $80 \%$ and $54 \%$ while the $\mathrm{HCl}$ concentration reached $3 \mathrm{M}$ and $6 \mathrm{M}$, respectively. Gold adsorption decreased more deeply, the extraction percentage fallen to less than $40 \%$ for an $\mathrm{HCl}$ concentration of $3 \mathrm{M}$. Therefore, the acid concentration in electronic wastewater must be controlled, dilution and $\mathrm{pH}$ adjustment must be used.

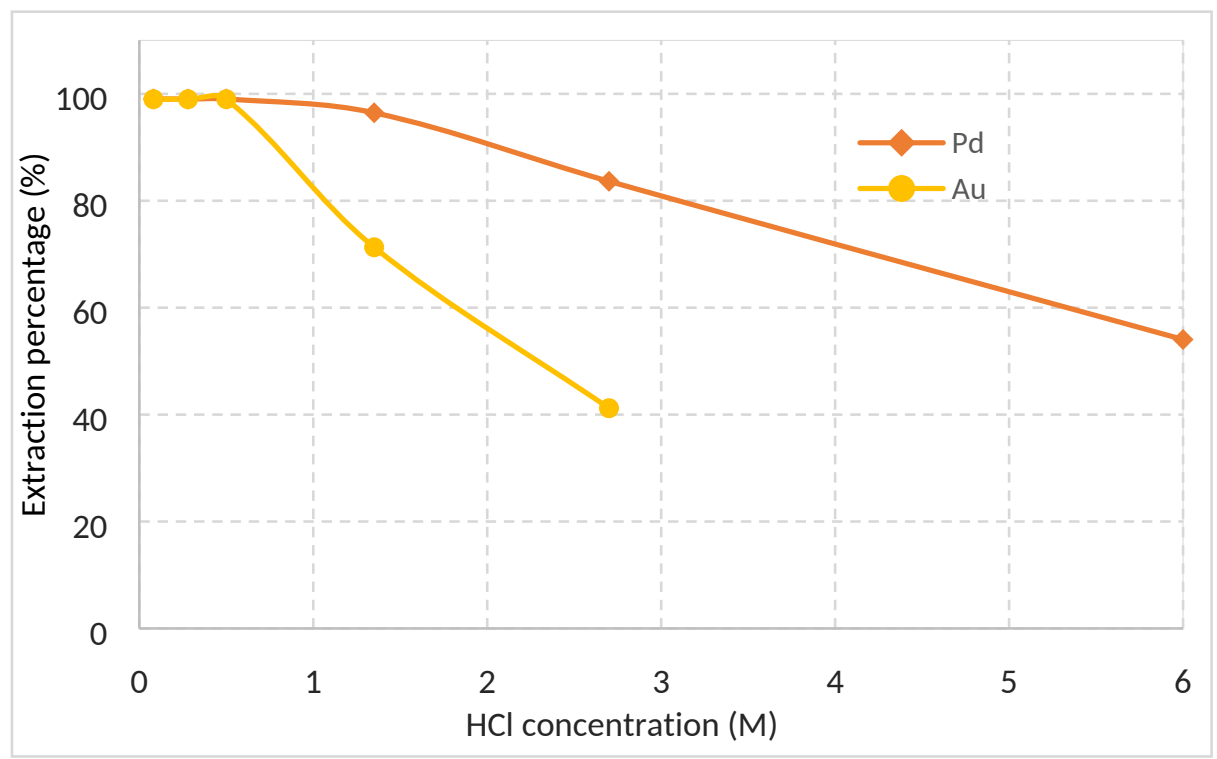

Figure 6. Effect of $\mathrm{HCl}$ concentration on adsorption capability of $\mathrm{ZrO}_{2}$-TOA

The effect of $\mathrm{Cl}^{-}$concentration was also studied by performing adsorption experiments in which $\mathrm{Pd}^{2+}$ solutions at $10 \mathrm{mg} / \mathrm{L}$ were prepared with a constant concentration of $\mathrm{H}^{+}$at $0.5 \mathrm{M}$ and a variable concentration of $\mathrm{Cl}^{-}$from 0.6 to $4 \mathrm{M}$. Figure 7 shows that chloride concentration had no effect on adsorption performance. The Pd extraction percentages were higher than $99 \%$ in the $\mathrm{Cl}^{-}$ concentration range studied from 0.6 to $4 \mathrm{M}$. 


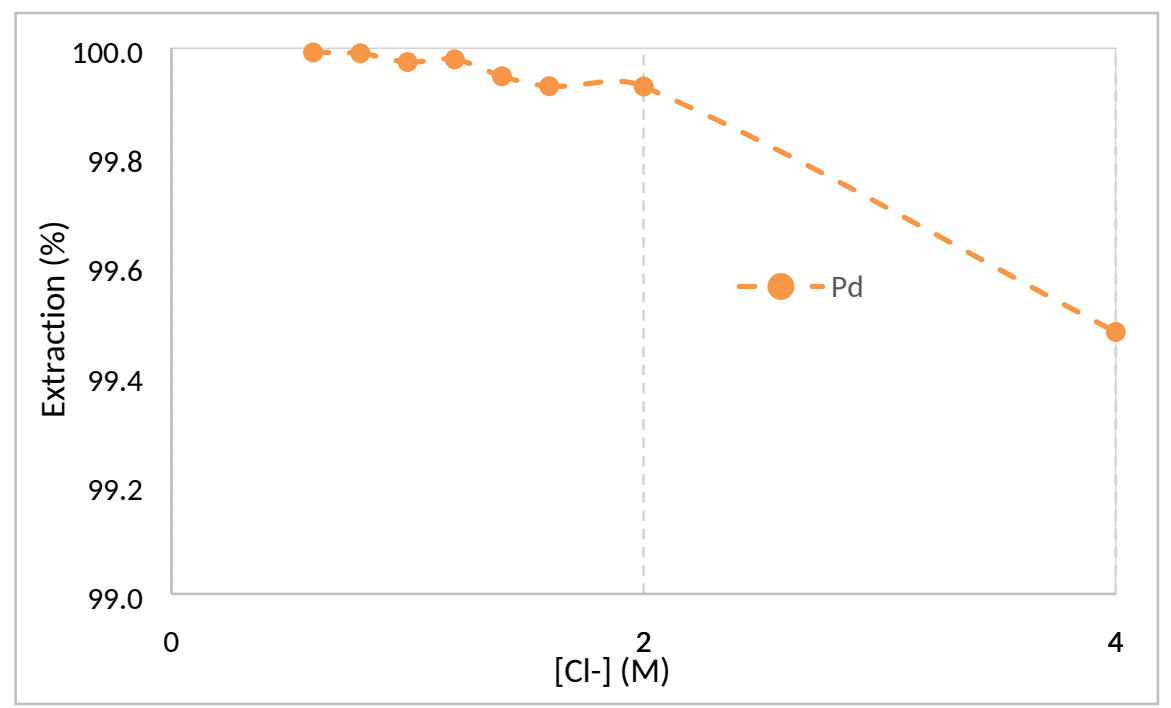

Figure 7. Effect of chloride concentration $(\mathrm{NaCl})$ on $\mathrm{Pd}$ adsorption capability of $\mathrm{ZrO}_{2}-\mathrm{TOA}(\mathrm{pH}=0.3)$

Thermodynamic study: Adsorption capacities of $\mathrm{ZrO}_{2}$-TOA toward Pd and Au ions According to Error! Reference source not found.8, the adsorption data from $\mathrm{ZrO}_{2}-\mathrm{TOA}$ to $\mathrm{Pd}^{2+}$ and $\mathrm{Au}^{3+}$ showed a similar two-step trend: (i) rapid increase in the low concentration range (0 $20 \mathrm{mg} / \mathrm{L}$ ) with a linear correlation between capacity and initial concentration; (ii) nonproportionally increasing relationship to higher initial concentrations, which seems to reach a plateau in the range above $100 \mathrm{mg} / \mathrm{L}$. A plausible reason for this trend was that at low concentrations all active sites on the zirconia surface are sufficient for the adsorption process; however, at high concentrations, the presence of former $\mathrm{Pd}^{2+}$ and $\mathrm{Au}^{3+}$ ions limits the accessibility of the zirconia surface and the adsorption of additional cations. 


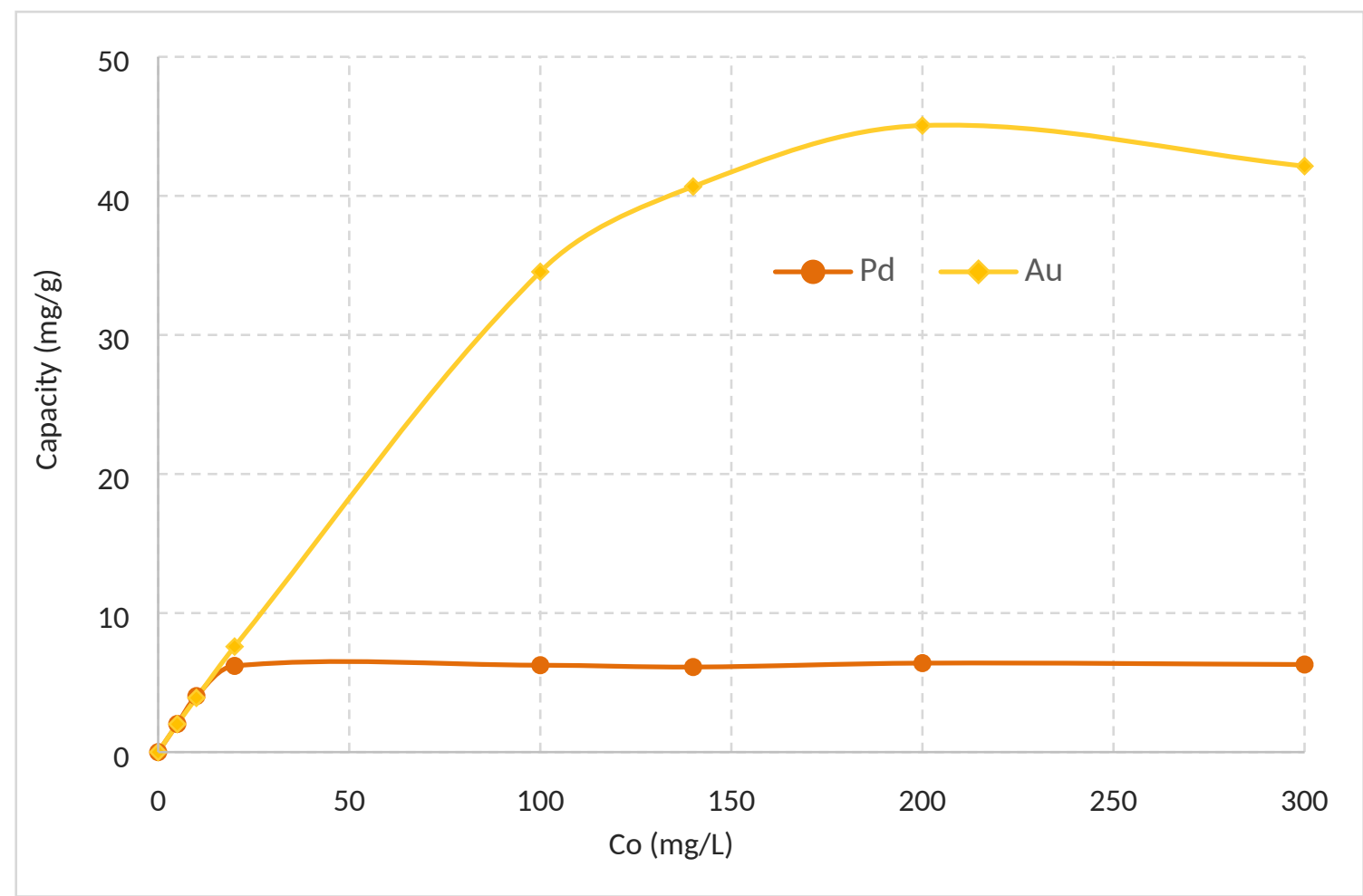

Figure 8. Adsorption capacities from $\mathrm{ZrO}_{2}$-TOA to $\mathrm{Pd}$ and $\mathrm{Au}(\mathrm{pH}=0.3)$

A thorough study of the adsorption behavior of $\mathrm{Pd}^{2+}$ and $\mathrm{Au}^{3+}$ ions and the surface properties of $\mathrm{ZrO}_{2}$-TOA was investigated applying the adsorption data to Langmuir's isothermal adsorption model. According to this model, the surface of the adsorbent is assumed homogeneous in terms of adsorption energy and the adsorbates would form a single layer on the surface of the adsorbent. In other words, the active sites on the surface of the adsorbent are supposed to be finite and identical and the interaction between the adsorbates is considered absent. The mathematical formula of this theory is expressed as follows:

$$
q_{e}=q_{\max }\left(\frac{b C_{e}}{1+b C_{e}}\right)
$$

Where $b(\mathrm{~L} / \mathrm{mg})$ is the Langmuir equilibrium constant related to energy or binding affinity parameter of the adsorption system, $\mathrm{q}_{\max }(\mathrm{mg} / \mathrm{g})$ is the maximum adsorption capacity, $\mathrm{C}_{\mathrm{e}}(\mathrm{mg} / \mathrm{L})$ is the equilibrium concentration, and $\mathrm{q}_{\mathrm{e}}(\mathrm{mg} / \mathrm{g})$ is the equilibrium capacity. The linear form of the Langmuir model is generally used to determine $b$ and $\mathrm{q}_{\max }$ : 


$$
\frac{C_{e}}{q_{e}}=\frac{1}{q_{\max } b}+\frac{C_{e}}{q_{\max }}
$$

Or $\frac{1}{q_{e}}=\frac{1}{q_{\max } b C_{e}}+\frac{1}{q_{\max }}$

Based on Pd and Au adsorption data, the linear regression of the Langmuir model was fitted. From the correlation coefficients $\mathrm{R}^{2}$ value, respectively 0.993 and 0.999 for $\mathrm{Pd}^{2+}$ and $\mathrm{Au}^{3+}$, it is clear that the Langmuir model of adsorption fits with our experimental results. The maximum sorption capacities $\mathrm{q}_{\max }$ for $\mathrm{Pd}^{2+}$ and $\mathrm{Au}^{3+}$ calculated from the curves were $6.3 \mathrm{mg} / \mathrm{g}$ and $44.6 \mathrm{mg} / \mathrm{g}$ respectively. A good agreement between experimental and calculated capacities supported the Langmuir model. It was interesting to note that the constant b values assigned and adjusted for molecular weight ${ }^{29}$ of the Langmuir model showed a higher affinity of TOA for Pd (b = 8.9 L.mg ${ }^{-1}$; $\left.b_{\text {adjusted }}=943.5 \times 10^{3} \mathrm{~L} \cdot \mathrm{mol}^{-1}\right)$ than for Au $\left(b=0.29 \mathrm{~L} \cdot \mathrm{mg}^{-1} ; b_{\text {adjusted }}=57.6 \times 10^{3} \mathrm{~L} \cdot \mathrm{mol}^{-1}\right)$.

\section{Kinetic study: effect of contact time}

In liquid-solid adsorption studies, the contact time required to achieve adsorption equilibrium is one of the crucial parameters that sheds light on the adsorption mechanism. The adsorption capacities to $\mathrm{Pd}^{2+}$ and $\mathrm{Au}^{3+}$ were monitored by varying the contact time from 15 to $360 \mathrm{~min}$. The results in Figure 9 show that the minimum contact time required for adsorption capacities to $\mathrm{Pd}^{2+}$ and $\mathrm{Au}^{3+}$ to reach a plateau was about 200 minutes.

Table 4 summarizes some critical parameters associated with pseudo-first-order and pseudosecond order kinetic adsorption models for Pd and Au. In two models, the pseudo-second order adsorption kinetics model is suitable for describing the adsorption process as a function of time with a correlation coefficient greater than 0.999. In the solid-liquid adsorption process, three steps are assumed to be involved: (i) external mass diffusion, (ii) intra-particle diffusion (pores) and (iii) interaction step ${ }^{30}$. During the adsorption process, stirring was used to accelerate the external mass transfer, so that intra-particle diffusion and chemical reaction became the flow control steps. Considering the chemical interaction between $\mathrm{ZrO}_{2}-\mathrm{TOA}$ and $\left[\mathrm{PdCl}_{4}\right]_{2}^{-}$or $\left[\mathrm{AuCl}_{4}\right]^{-}$, Pearson's theory, that predicts the stability of coordination between target metals and sulphur sites on the surface of $\mathrm{ZrO}_{2}$, is a plausible justification for adjusting the pseudo-second model. Essentially, the principle of the pseudo-first and pseudo-second models is based on a general equation ${ }^{31}$, but the 
magnitude of the concentration relative to the sites on the adsorbent decides which model best describes the adsorption process. In other words, the adsorption process follows the pseudo-second model at the low initial concentration (ppm-ppb) and the pseudo-primary model at the high initial concentration.

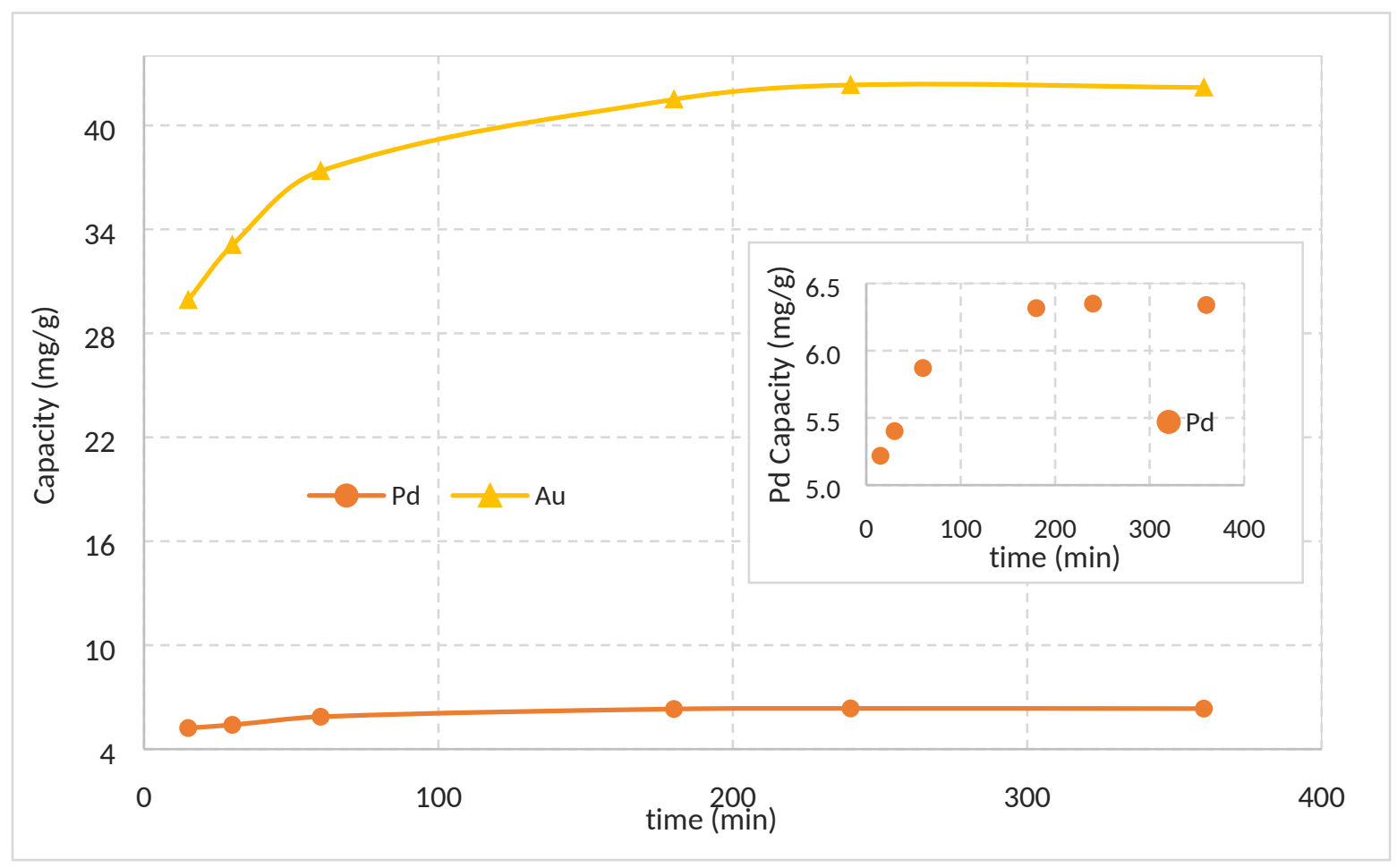

Figure 9. Effect of contact time on the adsorption capacities of $\mathrm{ZrO}_{2}-\mathrm{TOA}$ for $\mathrm{Pd}$ and $\mathrm{Au}(\mathrm{pH}=0.3)$

Table 4. Summary of adsorption kinetic parameters of $\mathrm{Pd}$ and $\mathrm{Au}$ on $\mathrm{ZrO}_{2}-\mathrm{TOA}$

\begin{tabular}{|c|c|c|}
\hline Model & Pd & Au \\
\hline Pseudo-first-order & 0.00178 & 0.00152 \\
$\mathrm{k}_{1}\left(\mathrm{~min}^{-1}\right)$ & 1.9 & 12.8 \\
$\mathrm{q}_{\mathrm{e}}\left(\mathrm{mg} \mathrm{g}^{-1}\right)$ & 0.8474 & 0.8670 \\
$\mathrm{R}^{2}$ & & \\
\hline Pseudo-second-order & 0.0218 & 0.000538 \\
$\mathrm{k}_{2}\left(\mathrm{~g} \mathrm{mg}^{-1}\right.$ min $\left.^{-1}\right)$ & $\mathbf{6 . 9}$ & $\mathbf{4 3 . 1}$ \\
$\mathrm{q}_{\mathrm{e}}\left(\mathrm{mg} \mathrm{g}^{-1}\right)$ & 0.9992 & 0.9990 \\
$\mathrm{R}^{2}$ & \\
\hline
\end{tabular}


A plausible explanation for this phenomenon, which is illustrated in Figure 10, is that adsorption is likely to be inhibited/decreased due to (i) the shift of the equilibrium to the left due to the high concentration of $\mathrm{Cl}^{-}$which promotes tetrachloro complexes of $\mathrm{Au}$ and $\mathrm{Pd}$ (according to equations 1 and 2) or (ii) protonation of sulphur sites when the concentration of $\mathrm{H}^{+}$is greater than $1 \mathrm{M}$ which prevents the complexing of $\mathrm{Au}$ and Pd species in the TOA solution on the surface of the zirconia ${ }^{24}$ and/or (iii) hydrolysis of the $\mathrm{Zr}-\mathrm{O}-\mathrm{C}$ bonds leading to cleavage between thioctic acid and $\mathrm{ZrO}_{2}$ surface.

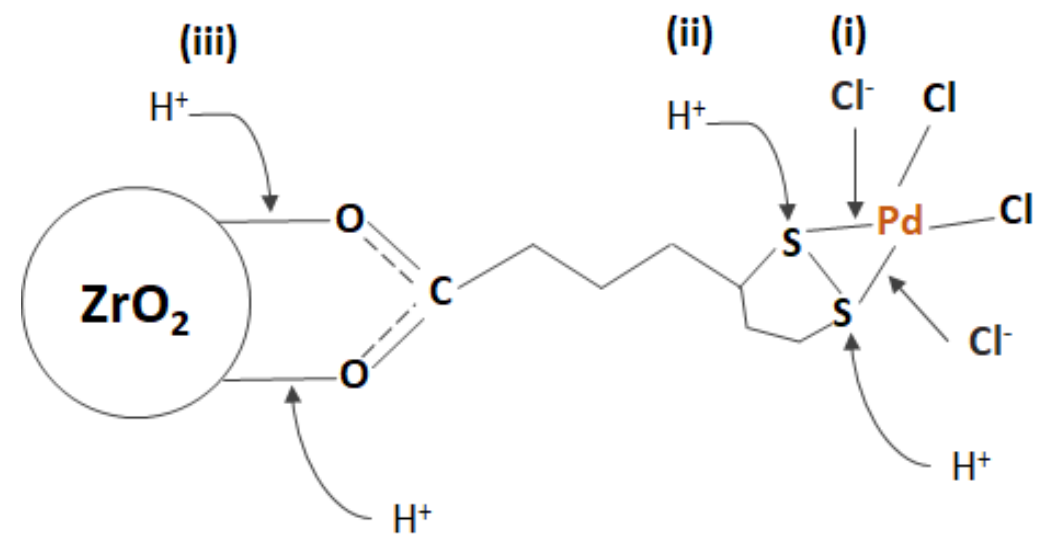

Figure 10. Schematic representation of three plausible causes responsible for the declining extraction performance at elevated concentration of hydrochloric acid.

Selectivity and reusability of the $\mathrm{ZrO}_{2}-\mathrm{TOA}$ nano-absorbent

The feasibility of using $\mathrm{ZrO}_{2}-\mathrm{TOA}$ in the ionic adsorption of $\mathrm{Pd}^{2+}$ and $\mathrm{Au}^{3+}$ has been realized with real industrial electronic wastewater effluents (from Morphosis) to obtain information not only on the adsorption performance but also on the selectivity of $\mathrm{Pd}^{2+}$ and $\mathrm{Au}^{3+}$. The initial effluent was diluted 5 times to reduce the acid concentration to a pH around 1, then $\mathrm{Pd}$ and $\mathrm{Au}$ in $25 \mathrm{~mL}$ of this solution were recovered with $\mathrm{ZrO}_{2}-\mathrm{TOA}$ and desorbed with a $0.2 \mathrm{M} / \mathrm{HCl} 0.5 \mathrm{M}$ thiourea mixture. The results presented in Figure 11 demonstrate the selectivity of our TOA-based system for Pd, even though $\mathrm{Cu}, \mathrm{Ni}$, Fe coexist at dominant concentrations (initial concentrations: $[\mathrm{Fe}]=4600$ $\mathrm{mg} / \mathrm{L},[\mathrm{Ni}]=3940 \mathrm{mg} / \mathrm{L},[\mathrm{Cu}]=1320 \mathrm{mg} / \mathrm{L},[\mathrm{Pd}]=1.58 \mathrm{mg} / \mathrm{L},[\mathrm{Au}]=0.12 \mathrm{mg} / \mathrm{L})$. The initial concentration of Au was too low to obtain relevant results. 


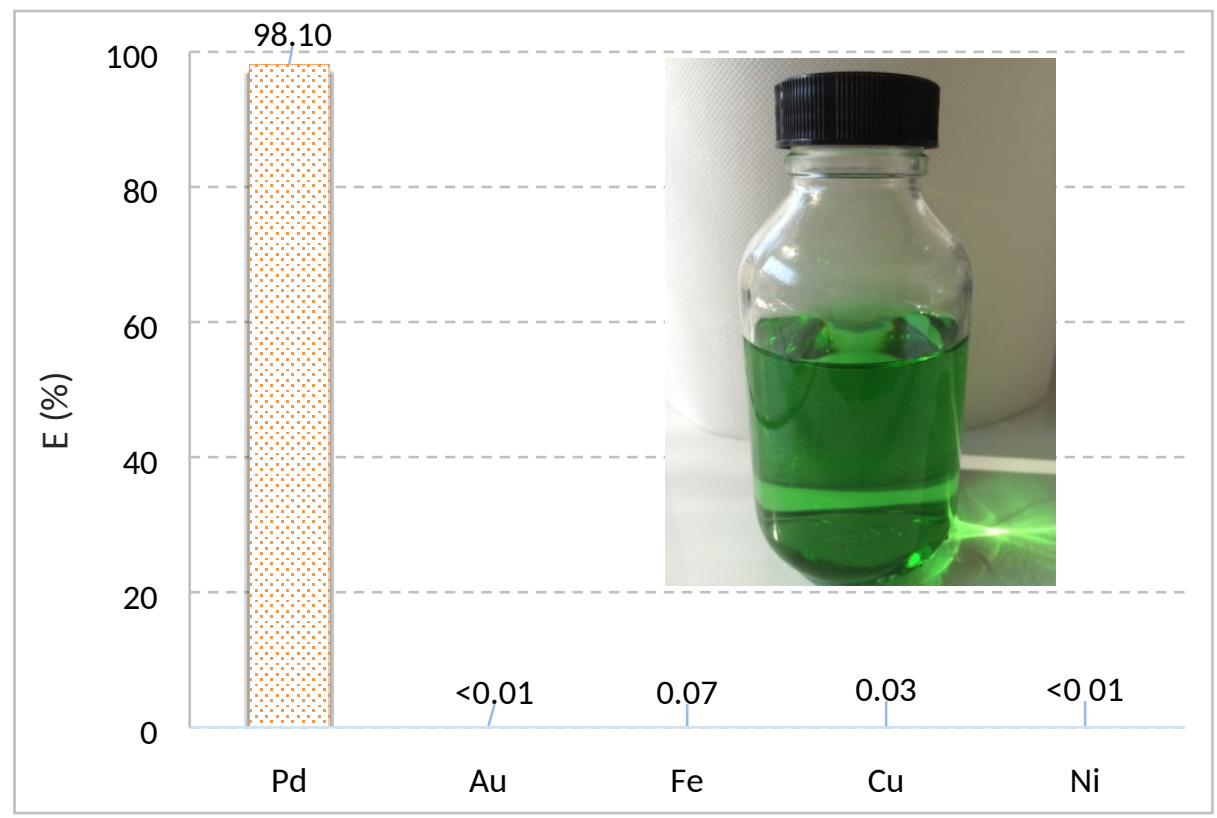

Figure 11. Adsorption extraction from $\mathrm{ZrO}_{2}-\mathrm{TOA}$ to $\mathrm{Pd}^{2+}$ and $\mathrm{Au}^{3+}$ in the industrial electronic wastewater $(\mathrm{pH}=1)$

The regeneration and reuse of the hybrid material $\mathrm{ZrO}_{2}-\mathrm{TOA}$ was tested by repeating $\mathrm{Pd}$ ion adsorption/desorption cycles up to four times in a "model" standard solution $\left(20 \mathrm{~mL} \mathrm{Pd}^{2+}\right.$ at 10 $\mathrm{mg} / \mathrm{L}$ ) and real industrial effluents $\left(\mathrm{Pd}^{2+}\right.$ at $1.58 \mathrm{mg} / \mathrm{L}$ and $\left.1 \mathrm{pH}\right)$. As shown in Figure 12 and Figure S6, the adsorption capacity from $\mathrm{ZrO}_{2}$-TOA to Pd decreases after each adsorption/desorption cycle. It should be noted that the $\mathrm{Pd}$ and $\mathrm{Au}$ ions were stripped off quantitatively using the optimized mixture of $0.2 \mathrm{M}$ thiourea and $0.5 \mathrm{M} \mathrm{HCl}$ in the desorption step.

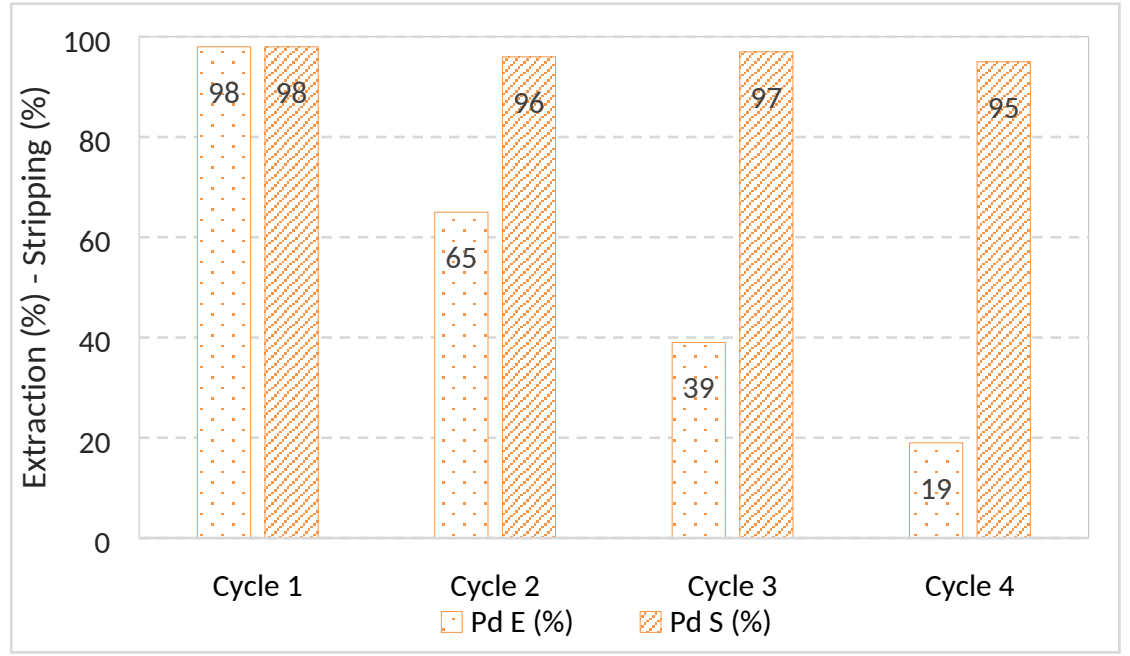

Figure 12. Reusability test of $\mathrm{ZrO}_{2}$-TOA for Pd adsorption in the standard solution at $10 \mathrm{mg} / \mathrm{L}$ through four cycles of adsorption/desorption $(\mathrm{pH}=0.3)$ 
With regard to cost-effectiveness, an adsorbent used in recycling applications should be a result of the ease of synthesis as well as a reusable material. Such results prompted us to investigate the same adsorption studies using a more robust system such as $\mathrm{ZrO}_{2}$-AA-TOA materials.

\subsection{2 $\mathrm{ZrO}_{2}$-AA-TOA nano-absorbent}

Kinetic study

As with nano- $\mathrm{ZrO}_{2}$ directly modified by TOA, the study of adsorption kinetics using nano- $\mathrm{ZrO}_{2}$ AA-TOA was conducted to verify whether the surface modification method could modify the adsorption process. A $10 \mathrm{mg} / \mathrm{L} \mathrm{Pd}$ standard solution was used to study the adsorption capacity of Pd as a function of contact time. The contact time required for Pd adsorption to reach saturation (60 min) was shorter than that of $\mathrm{ZrO}_{2}$-TOA, probably due to the lower disulfide content. (Figure S7a). In addition, the adsorption data also demonstrated that the adsorption process is similar to that of $\mathrm{ZrO}_{2}$-TOA due to the relevance of the pseudo-second adsorption kinetic model to describe the adsorption process (Figure S7b).

Reusability of the surface-modified $\mathrm{ZrO}_{2}$-AA-TOA materials

The two-step surface modification significantly improved the reusability of the materials obtained and approximately $95 \%$ of the extraction percentage was maintained after four adsorption/stripping cycles using either a standard $10 \mathrm{ppm}$ palladium solution (Figure 13) or a Morphosis industrial wastewater effluent (Figure 14). 


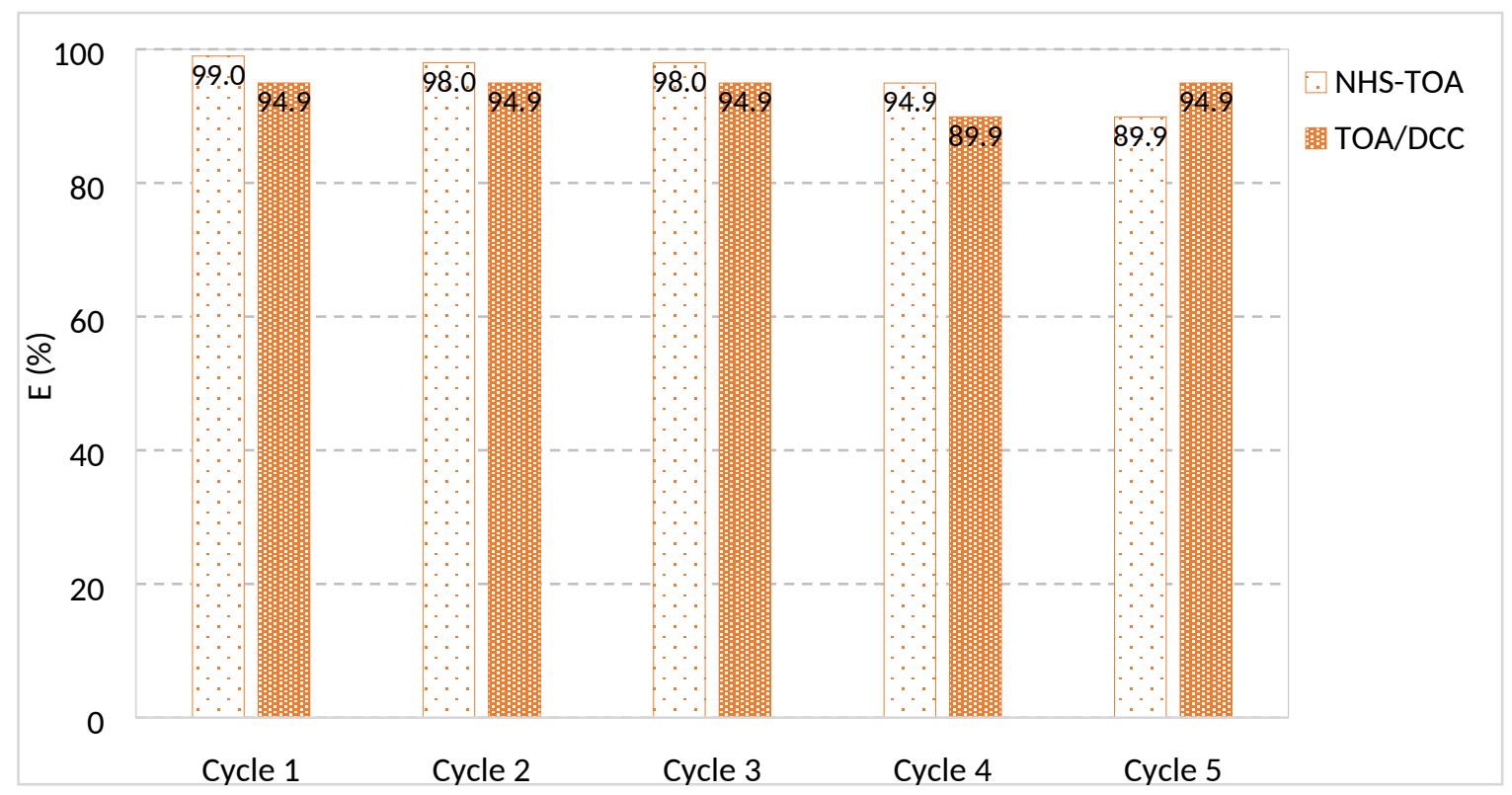

Figure 13. Reuse test of $\mathrm{ZrO}_{2}$-AA-TOA materials for the adsorption of Pd ions in the $10 \mathrm{mg} / \mathrm{L}$ standard solution by 5 adsorption/desorption cycles. $(\mathrm{pH}=0.3)$

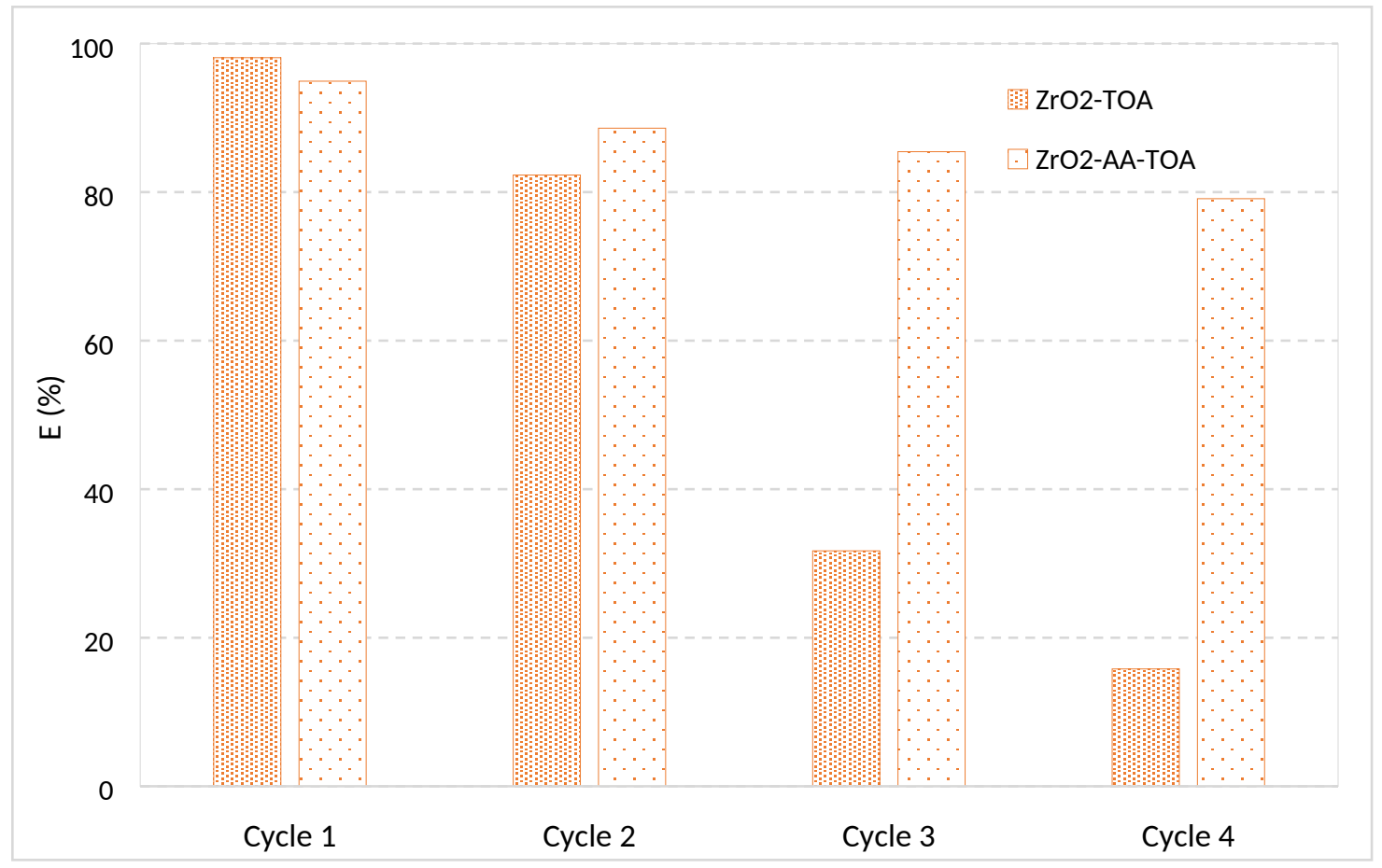

Figure 14. Comparison of the reusability of $\mathrm{ZrO}_{2}$-TOA and $\mathrm{ZrO}_{2}-\mathrm{AA}-\mathrm{TOA}$ to $\mathrm{Pd}$ in real electronic wastewater at $\mathrm{pH}$ $=0.3$. 
In conclusion, the two-step surface modification process appears to be a very promising alternative path that bypasses $\mathrm{ZrO}_{2}$-TOA's reuse deficiencies under the harsh conditions of industrial recycling effluents while maintaining good adsorption capabilities and kinetic performances.

\section{CONCLUSIONS}

Surface modifications of commercial nano- $\mathrm{ZrO}_{2}$ by different strategies, including direct grafting of thioctic acid (TOA) and a two-step modification process via an initial alendronic acid (AA) grafting and subsequent amide coupling of TOA, have been developed and optimized. They made it possible to compare the performance of both hybrid $\mathrm{ZrO}_{2}$-based nano-absorbents $\left(\mathrm{ZrO}_{2}\right.$-TOA and $\mathrm{ZrO}_{2}$-AA-TOA) for the recycling of precious metals such as gold and palladium from industrial electronic waste. Our systems have remarkable selectivities that have allowed us to recover precious metals ( $\mathrm{Pd}$ and $\mathrm{Au})$ quantitatively and at trace level (<10ppm) from the complex mixture of Ni, Fe, Cu provided by the industrial partner (Morphosis). The need to work in highly acidic and oxidizing environments created major difficulties in terms of reusability. These could be solved thanks to the grafting stability of bis-phosphonate ligands, such as alendronic acid, without loss of efficacy and selectivity. This study highlighted the importance of the stability of the binding of the organic group on the surface of nano-objects and in particular that of phosphonate groups for applications in harsh environments. This promising approach (which only uses commercial products) can be extended to other fields of application due to the chemical versatility of the alendronate ligand and the multitude of possible functionalizations via its $\mathrm{NH}_{2}$ function.

\section{ASSOCIATED CONTENT}

\section{Supporting Information}

Supplementary data associated with this article can be found, in the online version

Powder XRD of the commercial $\mathrm{ZrO}_{2}$ support; TEM images of bare $\mathrm{ZrO}_{2}, \mathrm{ZrO}_{2}-\mathrm{TOA}$, $\mathrm{ZrO}_{2}$-AA-TOA; ${ }^{31} \mathrm{P}$ MAS solid state NMR of TGA residues at $900^{\circ} \mathrm{C}$ of $\mathrm{ZrO}_{2}-\mathrm{AA}$ and $\mathrm{ZrO}_{2}$-AA-TOA; ATR-FTIR spectra of $\mathrm{ZrO}_{2}$-AA, $\mathrm{ZrO}_{2}-\mathrm{AA}-\mathrm{TOA}$ and $\mathrm{ZrO}_{2}$-TOA. Extraction percentage of $\mathrm{ZrO}_{2}$-TOA (\%) toward Pd through adsorption/desorption cycles 
in the real effluent ( $\mathrm{pH}=1$ ); Effect of contact time on adsorption capacities of $\mathrm{ZrO}_{2}$-AATOA (A) and pseudo-second order model of Pd adsorption kinetics (B).

\section{AUTHORS INFORMATION}

Corresponding Author

*Prof. Stephane DANIELE

§Present address: C2P2-UMR 5265, ESCPE-Lyon, BP 2077, 69616 Villeurbanne cedex, France Phone: + 33(0)47431808. E-mail: stephane.daniele@univ-lyon1.fr

TPresent address: Faculty of Environmental and Food Engineering, Nguyen Tat Thanh University, Ho Chi Minh City, Vietnam.

\section{ORCID}

Stephane Daniele: 0000-0003-4526-3835

Stephane Pellet-Rostaing: 0000-0003-3399-7153

Guilhem Arrachart: 0000-0002-5277-3967

\section{Notes}

The authors declare no competing financial interest.

\section{ACKNOWLEDGEMENT}

Q.T.A would like to acknowledge the program “Bourse d'Excellence de l'Ambassade de France au Vietnam” for scholarship funding and the company MORPHOSIS for financial support. The authors are also grateful to Pascale MASCUNAN from IRCELYON (Villeurbanne, UMR 5256) for conducting P, Pd and Au determination on ICP-OES, Chantal LORENTZ for ${ }^{31} \mathrm{P}$-solid stateNMR measurements from IRCELYON (Villeurbanne, UMR 5256), Kai Chung SZETO for DRIFT experiments from C2P2/CPE Lyon laboratory (Villeurbanne, UMR 5265).

\section{REFERENCES}

1. Kumar, A.; Holuszko, M.; Espinosa, D. C. R., E-waste: An overview on generation, collection, legislation and recycling practices. Resources, Conservation and Recycling 2017, 122, 32-42.

2. Baldé, C. P., Forti V., Gray, V., Kuehr, R., Stegmann, P. The Global E-waste Monitor 2017; 2017.

3. Lu, Y.; Xu, Z., Precious metals recovery from waste printed circuit boards: A review for current status and perspective. Resources, Conservation and Recycling 2016, 113, 28-39. 
4. $\quad$ Nguyen, N. V.; Jeong, J.; Jha, M. K.; Lee, J.-c.; Osseo-Asare, K., Comparative studies on the adsorption of $\mathrm{Au}(\mathrm{III})$ from waste rinse water of semiconductor industry using various resins. Hydrometallurgy 2010, 105 (1), 161-167.

5. $\quad$ Shen, S.; Pan, T.; Liu, X.; Yuan, L.; Zhang, Y.; Wang, J.; Guo, Z., Adsorption of Pd(II) complexes from chloride solutions obtained by leaching chlorinated spent automotive catalysts on ion exchange resin Diaion WA21J. Journal of Colloid and Interface Science 2010, 345 (1), 12-18. 6. Iglesias, M.; Anticó, E.; Salvadó, V., Recovery of palladium(II) and gold(III) from diluted liquors using the resin duolite GT-73. Analytica Chimica Acta 1999, 381 (1), 61-67.

7. Donia, A. M.; Atia, A. A.; Elwakeel, K. Z., Gold(III) recovery using synthetic chelating resins with amine, thio and amine/mercaptan functionalities. Separation and Purification Technology 2005, 42 (2), 111-116.

8. Sánchez, J. M.; Hidalgo, M.; Salvadó, V., A Comparison of the Separation Behavior of Some New Coordinating Resins and Commercial Quaternary Ammonium Resins with Reference to Their Separation of Gold(III) and Palladium(II) in Hydrochloric Acid Media. Solvent Extraction and Ion Exchange 2004, 22 (2), 285-303.

9. $\quad$ Muşină, A.; Bocokić, V.; Lavric, V.; van Zutphen, S., Phosphorus-Based Polymers for Selective Capture of Platinum Group Metals. Industrial \& Engineering Chemistry Research 2014, 53 (34), 13362-13369.

10. Mutin, P. H.; Guerrero, G.; Vioux, A., Organic-inorganic hybrid materials based on organophosphorus coupling molecules: from metal phosphonates to surface modification of oxides. Comptes Rendus Chimie 2003, 6 (8-10), 1153-1164.

11. Pujari, S. P.; Scheres, L.; Marcelis, A. T. M.; Zuilhof, H., Covalent Surface Modification of Oxide Surfaces. Angewandte Chemie International Edition 2014, 53 (25), 6322-6356.

12. Bou Orm, N.; Trieu, Q.; Daniele, S., TiO2-Based Hybrid Nanocomposites Modified by Phosphonate Molecules as Selective PAH Adsorbents. Molecules 2018, 23 (11), 3046.

13. (a) Fotoohi, B.; Mercier, L., Some insights into the chemistry of gold adsorption by thiol and amine functionalized mesoporous silica in simulated thiosulfate system. Hydrometallurgy 2015, 156, 28-39; (b) Homchuen, P.; Alorro, R. D.; Hiroyoshi, N.; Sato, R.; Kijitani, H.; Ito, M., A Study on the Utilization of Magnetite for the Recovery of Platinum Group Metals from Chloride Solution. Mineral Processing and Extractive Metallurgy Review 2016, 37 (4), 246-254.

14. (a) Petit, M.; Monot, J., Functionalization of Zirconium Oxide Surfaces. In Chemistry of Organo-Hybrids, John Wiley \& Sons, Inc.: 2014; pp 168-199; (b) Ide, A.; Drisko, G. L.; Scales, N.; Luca, V.; Schiesser, C. H.; Caruso, R. A., Monitoring Bisphosphonate Surface Functionalization and Acid Stability of Hierarchically Porous Titanium Zirconium Oxides. Langmuir 2011, 27 (21), 12985-12995; (c) Luschtinetz, R.; Gemming, S.; Seifert, G., Anchoring functional molecules on $\mathrm{TiO}_{2}$ surfaces: A comparison between the carboxylic and the phosphonic acid group. European Physical Journal Plus 2011, 126 (10).

15. (a) de los Reyes, M.; Majewski, P. J.; Scales, N.; Luca, V., Hydrolytic Stability of Mesoporous Zirconium Titanate Frameworks Containing Coordinating Organic Functionalities. ACS applied materials \& interfaces 2013, 5 (10), 4120-4128; (b) Veliscek-Carolan, J.; Hanley, T. L.; Luca, V., Zirconium organophosphonates as high capacity, selective lanthanide sorbents. Separation and Purification Technology 2014, 129, 150-158.

16. Guerrero, G.; Mutin, P. H.; Vioux, A., Anchoring of Phosphonate and Phosphinate Coupling Molecules on Titania Particles. Chemistry of Materials 2001, 13 (11), 4367-4373.

17. Dobson, K. D.; McQuillan, A. J., In situ infrared spectroscopic analysis of the adsorption of aliphatic carboxylic acids to $\mathrm{TiO}_{2}, \mathrm{ZrO}_{2}, \mathrm{Al}_{2} \mathrm{O}_{3}$, and $\mathrm{Ta}_{2} \mathrm{O}_{5}$ from aqueous solutions. 
Spectrochimica Acta Part A: Molecular and Biomolecular Spectroscopy 1999, 55 (7-8), 13951405.

18. Haberhauer, G.; Gerzabek, M. H., Drift and transmission FT-IR spectroscopy of forest soils: an approach to determine decomposition processes of forest litter. Vibrational Spectroscopy 1999, 19 (2), 413-417.

19. (a) Schmitt Pauly, C.; Genix, A.-C.; Alauzun, J. G.; Guerrero, G.; Appavou, M.-S.; Pérez, J.; Oberdisse, J.; Mutin, P. H., Simultaneous Phase Transfer and Surface Modification of TiO2 Nanoparticles Using Alkylphosphonic Acids: Optimization and Structure of the Organosols. Langmuir 2015, 31 (40), 10966-10974; (b) Pauly, C. S.; Genix, A.-C.; Alauzun, J. G.; Sztucki, M.; Oberdisse, J.; Hubert Mutin, P., Surface modification of alumina-coated silica nanoparticles in aqueous sols with phosphonic acids and impact on nanoparticle interactions. Physical Chemistry Chemical Physics 2015, 17 (29), 19173-19182.

20. Mao, J.; Mukherjee, S.; Zhang, Y.; Cao, R.; Sanders, J. M.; Song, Y.; Zhang, Y.; Meints, G. A.; Gao, Y. G.; Mukkamala, D.; Hudock, M. P.; Oldfield, E., Solid-State NMR, Crystallographic, and Computational Investigation of Bisphosphonates and Farnesyl Diphosphate Synthase-Bisphosphonate Complexes. Journal of the American Chemical Society 2006, 128 (45), 14485-14497.

21. Davidowski, S. K.; Holland, G. P., Solid-State NMR Characterization of Mixed Phosphonic Acid Ligand Binding and Organization on Silica Nanoparticles. Langmuir 2016, 32 (13), 3253-3261.

22. Gao, W.; Dickinson, L.; Grozinger, C.; Morin, F. G.; Reven, L., Self-Assembled Monolayers of Alkylphosphonic Acids on Metal Oxides. Langmuir 1996, 12 (26), 6429-6435.

23. Abd Razak, N. F.; Shamsuddin, M.; Lee, S. L., Adsorption kinetics and thermodynamics studies of gold(III) ions using thioctic acid functionalized silica coated magnetite nanoparticles. Chemical Engineering Research and Design 2018, 130, 18-28.

24. Sánchez, J. M.; Hidalgo, M.; Salvadó, V., The selective adsorption of gold (III) and palladium (II) on new phosphine sulphide-type chelating polymers bearing different spacer arms: Equilibrium and kinetic characterisation. Reactive and Functional Polymers 2001, 46 (3), 283291.

25. Kanagare, A. B.; Singh, K. K.; Kumar, M.; Yadav, M.; Ruhela, R.; Singh, A. K.; Kumar, A.; Shinde, V. S., DTDGA-Impregnated XAD-16 Beads for Separation of Gold from Electronic Waste Solutions. Industrial \& Engineering Chemistry Research 2016, 55 (49), 12644-12654.

26. Ruhela, R.; Singh, K.; Tomar, B. S.; Shesagiri, T. K.; Kumar, M.; Hubli, R. C.; Suri, A. K., Amberlite XAD-16 Functionalized with 2-Acetyl Amide Group for the Solid Phase Extraction and Recovery of Palladium from High Level Waste. Industrial \& Engineering Chemistry Research 2013, 52 (15), 5400-5406.

27. Yamada, M.; Gandhi, M. R.; Kondo, Y.; Haga, K.; Shibayama, A.; Hamada, F., Selective sorption of palladium by thiocarbamoyl-substituted thiacalix[n]arene derivatives immobilized on amberlite resin: application to leach liquors of automotive catalysts. RSC Advances 2015, 5 (74), 60506-60517.

28. (a) Gurung, M.; Adhikari, B. B.; Kawakita, H.; Ohto, K.; Inoue, K.; Alam, S., Selective Recovery of Precious Metals from Acidic Leach Liquor of Circuit Boards of Spent Mobile Phones Using Chemically Modified Persimmon Tannin Gel. Industrial \& Engineering Chemistry Research 2012, 51 (37), 11901-11913; (b) Nikoloski, A. N.; Ang, K.-L., Review of the Application of Ion Exchange Resins for the Recovery of Platinum-Group Metals From Hydrochloric Acid Solutions. Mineral Processing and Extractive Metallurgy Review 2014, 35 (6), 369-389. 
29. Ghosal, P. S.; Gupta, A. K., Determination of thermodynamic parameters from Langmuir isotherm constant-revisited. Journal of Molecular Liquids 2017, 225, 137-146.

30. Aghaei, E.; Alorro, D. R.; Encila, N. A.; Yoo, K., Magnetic Adsorbents for the Recovery of Precious Metals from Leach Solutions and Wastewater. Metals 2017, 7 (12), 529-541.

31. Azizian, S., Kinetic models of sorption: a theoretical analysis. Journal of Colloid and Interface Science 2004, 276 (1), 47-52. 